\title{
Development of high-throughput screening assays for profiling snake venom Phospholipase $A_{2}$ activity after high-resolution chromatographic fractionation
}

Kristina B.M. Still ${ }^{1,3}$, Julien Slagboom ${ }^{1,3}$, Sarah Kidwai ${ }^{1}$, Chunfang Xie ${ }^{1,3}$, Bastiaan Eisses ${ }^{1}$, Freek J. Vonk $^{2}$, Govert W. Somsen ${ }^{1,3}$, Nicholas R. Casewell ${ }^{4,5}$, Jeroen Kool ${ }^{1,3 *}$

${ }^{1}$ Division of BioAnalytical Chemistry, Amsterdam Institute of Molecular and Life Sciences, Vrije Universiteit Amsterdam, De Boelelaan 1085, 1081 HV Amsterdam, The Netherlands

${ }^{2}$ Naturalis Biodiversity Center, Leiden, The Netherlands

${ }^{3}$ Centre for Analytical Sciences Amsterdam (CASA), The Netherlands

${ }^{4}$ Centre for Snakebite Research \& Interventions, Liverpool School of Tropical Medicine, Pembroke Place, Liverpool, L3 5QA, UK

${ }^{5}$ Centre for Drugs and Diagnostics, Liverpool School of Tropical Medicine, Liverpool, L3 5QA, UK

*Corresponding author: j.kool@vu.nl 


\section{Abstract}

Many organisms, ranging from plants to mammals, contain phospholipase $A_{2}$ enzymes $\left(P_{2} A_{2}\right)$, which catalyze the production of lysophospholipids and fatty acid proinflammatory mediators. $\mathrm{PLA}_{2} \mathrm{~S}$ are also common constituents of animal venoms, including bees, scorpions and snakes, and they cause a wide variety of toxic effects including neuro-, myo-, cyto-, and cardio-toxicity, anticoagulation and edema. The aim of this study was to develop a generic method for profiling enzymatically active $\mathrm{PLA}_{2} \mathrm{~S}$ in snake venoms after chromatographic separation. For this, low-volume high-throughput assays for assessment of enzymatic PLA $\mathrm{A}_{2}$ activity were evaluated and optimized. Subsequently, the assays were incorporated into a nanofractionation platform that combines high-resolution fractionation of crude venoms by liquid chromatography (LC) with bioassaying in 384-well plate format, and parallel mass spectrometric (MS) detection for toxin identification. The miniaturized assays developed are based on absorbance or fluorescence detection (respectively, using cresol red or fluorescein as $\mathrm{pH}$ indicators) to monitor the $\mathrm{pH}$ drop associated with free fatty acid formation by enzymatically active $\mathrm{PLA}_{2} \mathrm{~S}$. The methodology was demonstrated for assessment of PLA 2 activity profiles of venoms from the snake species Bothrops asper, Echis carinatus, Echis coloratus, Echis ocellatus, Oxyuranus scutellatus and Daboia russelii russelii. 


\section{Introduction}

Phospholipase $A_{2}\left(P L A_{2}\right.$, EC 3.1.1.4) is a common enzyme occurring in many organisms, ranging from plants to mammals.[1] $\mathrm{PLA}_{2} \mathrm{~S}$ are crucial enzymes in lipid metabolism and lipid-protein interactions. They also play a significant role in various cellular processes such as biotransformation and digestion of phospholipids, signal transduction and host defense.[2] $\mathrm{PLA}_{2} \mathrm{~S}$ are connected to human pathophysiological events and associated with certain types of cancers, arthritis, and inflammatory disorders, and therefore have been studied extensively.[3-5]

$\mathrm{PLA}_{2} \mathrm{~S}$ are also widely distributed in animal venoms. Snake venom PLA $\mathrm{A}_{2}(\mathrm{SVPLA} 2 \mathrm{~S})$ can be major toxin components - they often comprise $30-71 \%$ of the total venom proteins, and they can also be diverse in terms of amino acid composition, as evidenced by the UniProtKB database containing over 400 unique $\operatorname{svPLA}_{2}$ s.[6] In addition to catalyzing the production of lysophospholipids and fatty acid pro-inflammatory mediators, $\mathrm{sVPLA}_{2} \mathrm{~s}$ are multifunctional enzymes and cause a wide variety of toxic effects ranging from neurotoxicity, myotoxicity, anticoagulant effects, cytotoxicity, cardiotoxicity, to edema.[7] Because of the pathological consequences of these toxins to prey and snakebite victims, $\operatorname{SVPLA}_{2} \mathrm{~s}$ have been extensively investigated.[7,8] Since May 2018, snake envenoming has been categorized as one of the most neglected tropical diseases.[9] The annual number of human snakebites is estimated to be between 1.8 and 2.7 million worldwide, resulting in 81,000-138,000 deaths and around three times more cases of permanent morbidity cases.[10] Many victims receive inadequate treatment or no treatment at all. The World Health Organization (WHO) has therefore adopted a resolution towards tackling this devastating global health problem.[10]

Snake venoms are complex biochemical mixtures that are injected via the fangs of snakes for killing prey and for defense. These venoms comprise many different pathological proteins and peptides, and other organic molecules. Venom composition is typically complex (50-200 proteins per species) and highly variable, with often extensive inter-specific, and even, intra-specific venom variations observed.[11,12] Rooted in the latter are geographical differences, living habitat, sex, and age of a snake, thereby increasing venom complexity even more.[13,14] Consequently, antivenom therapies, which are based on antibodies produced in horses or sheep following their immunization with venom or mixtures of venoms, are highly specific to those venoms used for production, but often lack efficacy for treating snakebites by other snake species.[12] In recent years, research efforts have increased on the potential utility of small molecule drugs as potential alternatives for 
conventional antivenom therapies. These promising approaches focus on neutralizing entire classes of venom enzymes, irrespective of sequence and structural variation, with small molecular inhibitors or metal chelators. For instance, recent studies have demonstrated that enzyme inhibitors and metal chelating agents, such as EDTA and DMPS, are capable of neutralizing snake venom metalloproteinase toxins in pre-clinical models of envenoming.[15,16] In relation to $\operatorname{svPLA}_{2} S$, a number of studies have explored the neutralizing potential of the generic PLA 2 inhibitors methyl-varespladib and varespladib.[17] These compounds show great promise for the future development of affordable, stable and broad-spectrum treatment for PLA -induced toxicities following snake envenoming. However, as SVPLA ${ }_{2} \mathrm{~S}$ are major venom toxins responsible for a diverse array of severe pathologies following envenoming, the development of analytics for rapid SVPLA $\mathrm{P}_{2}$ profiling after chromatographic separation of snake venoms - the approach described in this study is an essential prerequisite for efficient selection and in vitro validation of novel PLA $\mathrm{A}_{2}$ inhibiting agents.

Assays using chromogenic molecules for $\mathrm{PLA}_{2}$ profiling have previously been developed. $[18,19]$ One of these assays relies on hydrolysis of a substrate by PLA $\mathrm{A}_{2}$ into a coloured product, with ensuing absorbance measured at $425 \mathrm{~nm}$, as described by Petrovic et al.[18] In addition, both radioactivity based assays [20,21] and fluorogenic assays $[22,23]$ have been described. All these assay formats, however, are probe substrate dependent and thus dependent on the selectivity and enzymatic activity of each PLA for the probe substrate used. Assays for assessment of generic enzymatic PLA activity use a phospholipid as a generic substrate, in combination with $\mathrm{pH}$ indicators to measure medium acidification upon phospholipid hydrolysis.[24-26] This enzymatic reaction involves $\mathrm{PLA}_{2} \mathrm{~S}$ cleaving the sn-2 ester of phospholipids, generating a free fatty acid and a lyso-phosholipid. Price et al. and Lobo De Araljio et al. measured PLA 2 activity of crude snake venoms using the $\mathrm{pH}$ indicators bromothymol blue [26] and phenol red [27], respectively. These assays were performed in cuvettes, using a spectrophotometer, or in 96-well format. The use of bromothymol blue in a $\mathrm{PLA}_{2}$ assay was considered for this study, but was abandoned since literature reports this $\mathrm{pH}$ indicator to be able to inhibit phospholipase subunits under certain conditions.[27]

In this study, two assays for enzymatic PLA 2 activity were developed in 384-well format. One assay makes use of cresol red with colorimetric readout whereas the other uses fluorescein with fluorescence readout. The assays were optimized and validated for application in a workflow comprising high-resolution chromatographic fractionation of snake venoms followed by enzymatic PLA $\mathrm{A}_{2}$ bioassaying. For this, well plates with collected fractions 
were vacuum-centrifuged to dryness followed by robotic pipetting of bioassay reagents and plate reader based readout in order to assess $\mathrm{PLA}_{2}$ activities. The feasibility and usefulness of the approach for measuring generic SVPLA 2 activity profiles was demonstrated using medically relevant snake venoms from Bothrops asper, Echis carinatus, Echis coloratus, Echis ocellatus, Oxyuranus scutellatus and Daboia russelii russelii.

\section{Materials and Methods}

\subsection{Chemicals and biological reagents}

Water was purified with a Milli-Q Plus system (Millipore, Amsterdam, The Netherlands). DMSO was supplied by Riedel-de-Haën (Zwijndrecht, The Netherlands). Acetonitrile (ACN; ULC/MS grade) and formic acid (FA) were obtained from Biosolve (Valkenswaard, The Netherlands). All salts used for buffer preparation were of analytical grade and purchased from Merck (Kenilworth, USA), Fluka (Bucharest, Romania) or Sigma-Aldrich (Darmstadt, Germany). Micro- $90^{\circledR}$ concentrated cleaning solution was supplied by Sigma-Aldrich. Lyophilised snake venoms (see Table 1) were provided by the Centre for Snakebite Research \& Interventions (Liverpool School of Tropical Medicine, UK) and stored long-term at $-80{ }^{\circ} \mathrm{C}$. Stock solutions of crude venoms $(5.0 \mathrm{mg} / \mathrm{mL})$ were prepared in water prior to analysis and stored at $-80^{\circ} \mathrm{C}$. A $1 \mathrm{mM}$ Tris $(\mathrm{pH} 8)$ buffer solution for the bioassay was made in Milli-Q water and its $\mathrm{pH}$ was checked at room temperature. After preparation, the buffer was stored at $4{ }^{\circ} \mathrm{C}$ until use. Cresol red and fluorescein were from Sigma-Aldrich. The $5 \mathrm{mM}$ cresol red stock solution was prepared in methanol and stored at $-20{ }^{\circ} \mathrm{C}$. The $1 \mathrm{mM}$ fluorescein stock solution was prepared in DMSO and kept at $-80{ }^{\circ} \mathrm{C}$. Triton- $\mathrm{X}-100$ was purchased from Thermo Scientific (Landsmeer, Netherlands) and a stock solution of $170 \mathrm{mM}$ was prepared in milli-Q water and stored at $-20^{\circ} \mathrm{C}$. Phosphatidylcholine from soy beans was purchased from Sigma-Aldrich of which a stock solution of $20 \mathrm{mg} / \mathrm{mL}$ was prepared in methanol and kept at $-20^{\circ} \mathrm{C}$. 
Table 1. List of analyzed snake venoms and their abbreviations as used in this study.

\begin{tabular}{|l|l|l|}
\hline Snake venom & Origin & Abbreviation \\
\hline Bothrops asper & Costa Rica & BA \\
\hline Echis carinatus & India* & EC \\
\hline Echis coloratus & Egypt & ECO \\
\hline Echis ocellatus & Nigeria & EO \\
\hline Oxyuranus scutellatus & Australia & OS \\
\hline Daboia russelii russelii & Sri Lanka & DRR \\
\hline
\end{tabular}

* Note that the Indian $E$. carinatus venom was collected from a single specimen that was inadvertently imported to the UK via a boat shipment of stone, and then rehoused at LSTM on the request of the UK RSPCA.

\subsection{PLA $_{2}$ assay using cresol red as $\mathrm{pH}$ indicator}

Pre-prepared $1.0 \mathrm{mM}$ TRIS buffer solution was used at room temperature and $\mathrm{pH} 8.0$. The assay was performed with all other reagents at room temperature, which is crucial due to the $\mathrm{pH}$ dependence of the assay. For best performance the assay reagent mix was freshly prepared in a $50 \mathrm{~mL}$ PP Centrifuge tube (Corning Life Sciences B.V., Amsterdam, The Netherlands). The mix contained $\mathrm{NaCl}(75 \mathrm{mM}), \mathrm{KCl}(75 \mathrm{mM}), \mathrm{CaCl}_{2}(7.5 \mathrm{mM})$, Cresol Red $(0.037 \mathrm{mM})$, Triton-X-100 $(0.66 \mathrm{mM})$ and phosphatidylcholine $(0.66 \mathrm{mM})$ in $1.0 \mathrm{mM}$ Tris $(\mathrm{pH}$ 8.0). The salts were added as dry compounds (after accurate weighing), whereas for the other constituents, accurate volumes of the stock-solutions (Section 2.1) were used. Triton-X-100 is needed to increase the solubility of the substrate, improving the interaction between $\mathrm{PLA}_{2}$ and phosphatidylcholine. Direct addition of Triton-X-100 resulted in homogeneity problems and unsatisfactory assay performances. Therefore, the use of a preprepared stock solution of Triton-X-100 (170 mM) was used. The phosphatidylcholine solution was added last, as it slowly degrades upon contact with water. Prior to addition of phosphatidylcholine, the $\mathrm{pH}$ of the total solution was always checked and, if needed, adjusted to $\mathrm{pH}$ 8.0. The buffer capacity of the assay solution was low in order to allow measurement of a $\mathrm{pH}$ drop as result of PLA 2 activity. The assay was initiated by robotically pipetting $40 \mu \mathrm{L}$ of the final assay reagent mix into each plate well containing either vacuum centrifuge-dried snake venom fractions or $10 \mu \mathrm{L}$ of test solution used for assay development. In the latter case, concentrations of the assay mix constituents were adjusted to match the final assay concentrations stated above. The plate was placed in the plate reader within $5 \mathrm{~min}$ after pipetting, and the plate reader was thermostated at $25{ }^{\circ} \mathrm{C}$. The 
absorbance of each well content was measured at $572 \mathrm{~nm}$ with a Thermo Fisher Scientific Laboratory Varioskan $^{\text {TM }}$ LUX Multimode Microplate Reader using SkanIt 4.1 (Landsmeer, Netherlands). Measurements were performed in one kinetic loop with a total measurement time of $40 \mathrm{~min}$. Two data-processing options in the SkanIt 4.1 software were used to determine PLA $\mathrm{A}_{2}$ activity from the measured kinetic curves: (1) slope of a reading range (for well plates holding venom fractions), and (2) average rate in time per well (during assay development). For the latter, one measurement data point was plotted every 10 min over the total measuring curve. For constructing bioassay chromatograms of snake venoms, for each well the value resulting from the processed assay data was plotted against the LC elution time corresponding to the well.

\subsection{PLA $\mathrm{A}_{2}$ assay using fluorescein as $\mathrm{pH}$ indicator}

In this $\mathrm{PLA}_{2}$ activity assay fluorescein is used as a fluorescent $\mathrm{pH}$ indicator in black 384-well, F-shape microplates (Greiner Bio One, Alphen aan den Rijn, the Netherlands). A decrease in assay $\mathrm{pH}$ causes a decrease of fluorescence intensity. Concentrations and preparation of the assay reagents and mix were the same as for the colorimetric assay (Section 2.2), but no Cresol Red was added. Instead, fluorescein was present at a final concentration of $1 \mu \mathrm{M}$. The assay was started by using the same procedure as stated in Section 2.2. The plate reader temperature was set at $25{ }^{\circ} \mathrm{C}$ and of each well fluorescence was measured using an excitation wavelength of $488 \mathrm{~nm}$ and an emission wavelength of $520 \mathrm{~nm}$ in the Varioskan ${ }^{\mathrm{TM}}$ LUX Multimode Microplate Reader. Measurements were performed in one kinetic loop with a total measurement time of $40 \mathrm{~min}$. The bioassay data were presented as bioassay chromatograms when used for snake venom screening.

The cleaning procedure of the robotic pipetting machine is as reported previously in Still et al.[28] For typical kinetic curve results obtained when running both PLA $\mathrm{A}_{2}$ assay formats with venoms high in $\mathrm{PLA}_{2}$ abundance, the reader is referred to supporting information $\mathrm{S} 1$. The difference in curve slopes allows for the reconstruction of bioactivity chromatograms (more details in Section 3.3). 


\subsection{Instrumental setup for venom fractionation}

For high-resolution fractionation of snake venoms, the analytical system previously described by Still et al.[28] and by Mladic et al.[29] was used. Samples were injected with a Shimadzu SIL-30AC autosampler and LC separation was performed with a Shimadzu LC system controlled by Lab Solutions software. Gradient LC was performed using two Shimadzu LC-30AD pumps ( $A$ and $B$ ) operated at a total flow rate of $0.5 \mathrm{~mL} / \mathrm{min}$. Mobile phase $A$ was water-ACN-FA $(98: 2: 0.1, v / v / v)$ and mobile phase $B$ was water-ACN-FA (2:98:0.1, v/v/v). The gradient was as follows: $0 \%$ to $50 \%$ B (20 min), $50 \%$ to $90 \%$ B (4 $\mathrm{min}), 90 \%$ B (5 min), $90 \%$ to $0 \%$ B (1 min), 0\% B (10 min). A $150 \times 4.6 \mathrm{~mm}$ ID analytical column packed with $\mathrm{Xbridge}^{\mathrm{TM}} \mathrm{BEH} 300$ reversed-phase $\mathrm{C} 18$ material $(5 \mu \mathrm{m})$ was used for separations and was maintained at $37^{\circ} \mathrm{C}$ in a Shimadzu CTD-30A column oven. The column effluent was split in a 1:9 ratio using a low-dead-volume flow splitter. The flow of 0.05 $\mathrm{mL} / \mathrm{min}$ was either directed to waste or led to a high-resolution time-of-flight (TOF) mass spectrometer for compound identification. During assay and method development, no MS data was acquired. The flow of $0.45 \mathrm{ml} / \mathrm{min}$ was led to a either a Gilson 235 robot programmed as fractionation device or a FractioMate ${ }^{\mathrm{TM}}$ fractionator (SPARK-Holland \& VU, Netherlands, Emmen \& Amsterdam) each providing fractions ( $6 \mathrm{~s} /$ well) onto clear or black 384-well plates. Fractionation was controlled by employing in-house written Ariadne software or FractioMator software (Spark-Holland \& VU), respectively. The plates with fractions were vacuum centrifuged to dryness at room temperature using a Christ Rotational Vacuum Concentrator RVC 2-33 CD plus (Salm en Kipp, Breukelen, the Netherlands) with a cooling trap at $-80^{\circ} \mathrm{C}$, and then stored at $-80^{\circ} \mathrm{C}$. 


\section{Results and Discussion}

This research focused on the development and optimization of enzymatic PLA $A_{2}$ activity assays suitable for application in the nanofractionation platform to allow profiling of venom fractions. For this, these assays should be sensitive, rapid, robust, and applicable to small LC fractions (collected in 384-well plate format). PLA $A_{2}$ catalyzes the hydrolysis of ester bonds of glycerophospholipids at position sn-2. PLA $A_{2}$ activity assaying can be based on the accompanying acidification of the reaction mixture caused by the formed free fatty acids during phosphatidylcholine hydrolysis. In presence of $\mathrm{pH}$ indicators, activity will cause measurable color changes. The use of bromothymol blue in the required miniaturized assay was considered for use in this study, however, (i) the literature reports this $\mathrm{pH}$ indicator to inhibit phospholipase subunits, [26] while pilot experiments using bromothymol blue for assaying venoms showed highly varying and non-repeatable results. Specifically, our pilot results appeared unrelated to $\mathrm{PLA}_{2}$ hydrolysis of phosphatidylcholine, and therefore bromothymol blue was not considered to be suitable for our purposes. Instead, we developed two assays suitable for 384-well format using phosphatidylcholine as a substrate, with either cresol red $(\mathrm{CR})$ as a color $\mathrm{pH}$ indicator or fluorescein as a fluorescent $\mathrm{pH}$ indicator.

\subsection{PLA 2 activity assay based on cresol red}

\subsubsection{Assay optimization}

Going from $\mathrm{pH} 8.8$ to 7.0, protonation of the $\mathrm{pH}$ indicator cresol red results in a color change from red to yellow. When cresol red is added to the assay reagent mixture, PLA 2 activity can be detected as a decrease in absorbance at $572 \mathrm{~nm} .[25,27]$ The $\mathrm{pH}$ of the assay solution was first adjusted to 8.0 in order to allow sensitive detection of the $\mathrm{pH}$ shift. Optimal conditions were studied and achieved in several optimization steps, as described below. More detailed information and results on the development of the cresol red-based $\mathrm{PLA}_{2}$ activity assay are provided in the supporting information S2 and S3.

The optimal concentrations for cresol red and the substrate phosphatidylcholine were studied by performing serial dilution experiments. Daboia russelii russelii (DRR) snake venom, which is known for its relatively high content of $\mathrm{SVPLA}_{2}$, was used as a test venom for assay optimization at a concentration of $12.5 \mu \mathrm{g} / \mathrm{mL}$.[11] Figure 1 shows time-course absorbance measurements in a cuvette using optimized assay conditions and DRR venom. 
The color change of cresol red over time is observed as an increasing absorbance at $430 \mathrm{~nm}$ and a decreasing absorbance at $570 \mathrm{~nm}$. As the absolute change is most substantial at 570 $\mathrm{nm}$, this wavelength was used for the readout of the cresol red-based PLA $\mathrm{P}_{2}$ assay. Higher concentrations of cresol red resulted in more intense red coloring of the assay mixture, detected as a higher absorbance at $572 \mathrm{~nm}$ at the start of the measurement (Figure S2). The optimal cresol red concentration was found to be $37 \mu \mathrm{M}$. Increasing the concentration of phosphatidylcholine resulted in an increased acidification of the assay mixture upon assay progression when $\operatorname{svPLA}_{2} \mathrm{~S}$ were present. The optimal substrate concentration was determined to be $0.66 \mathrm{mM}$. Concentrations of $0.66 \mathrm{mM}$ and $37 \mu \mathrm{M}$ for phosphatidylcholine and cresol red, respectively, were used in all subsequent experiments.

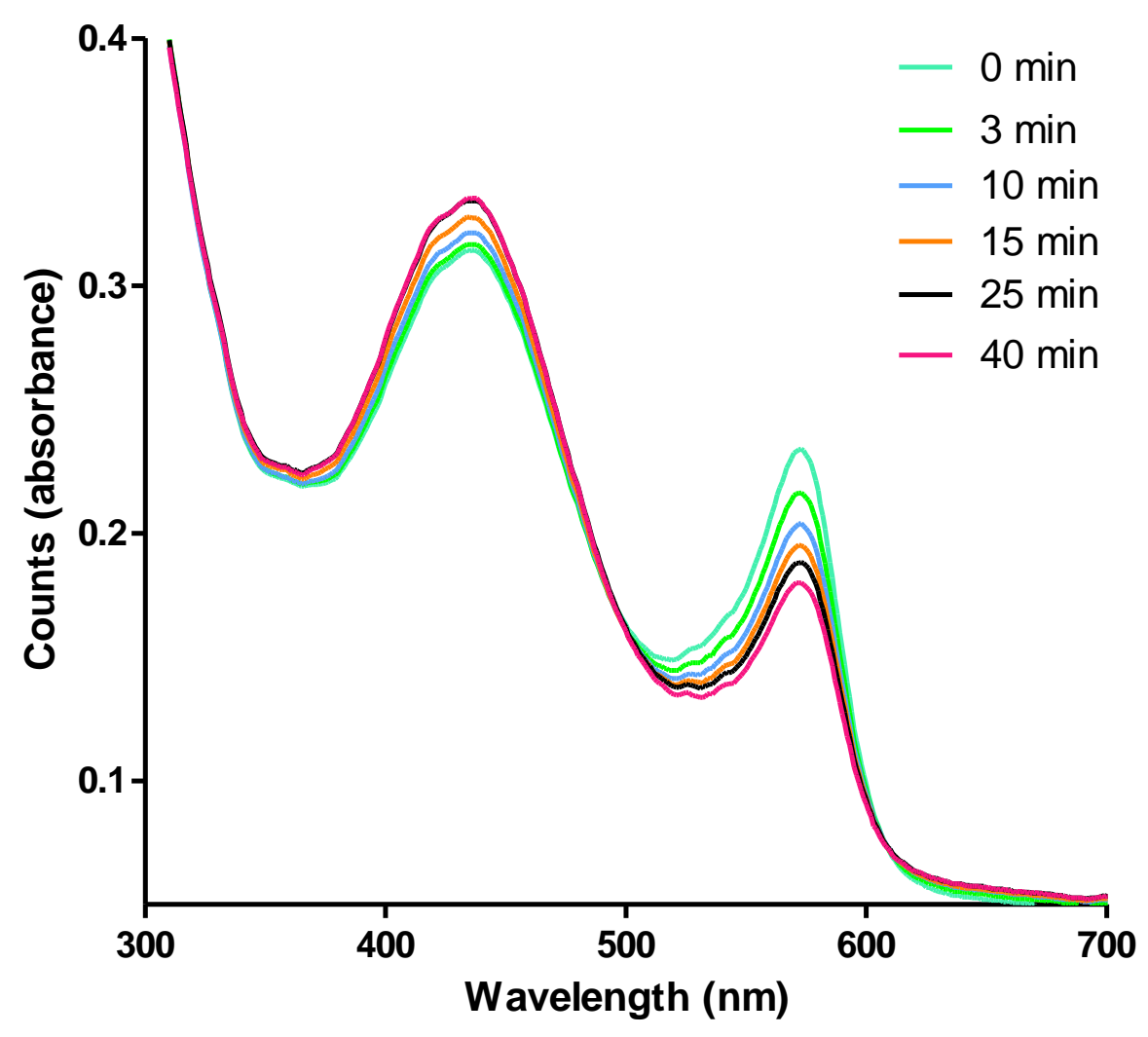

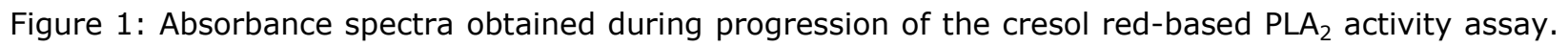
Conditions: phosphatidylcholine concentration, $0.66 \mathrm{mM}$; cresol red concentration, $37 \mu \mathrm{M}$; DRR venom concentration, $12.5 \mu \mathrm{g} / \mathrm{mL}$. 


\subsubsection{Assay evaluation}

The optimized assay was evaluated for sensitivity and limit of detection (LOD) by analyzing different concentrations of DRR snake venom.

The concentration-response plot for SVPLA 2 activity was assessed by analyzing a serial dilution series of DRR venom in water (freeze-dried after addition to the wells) with final assay concentrations of $50,25,12.5,6.3$ and $3.2 \mu \mathrm{g} / \mathrm{mL}$ (Figure 2).

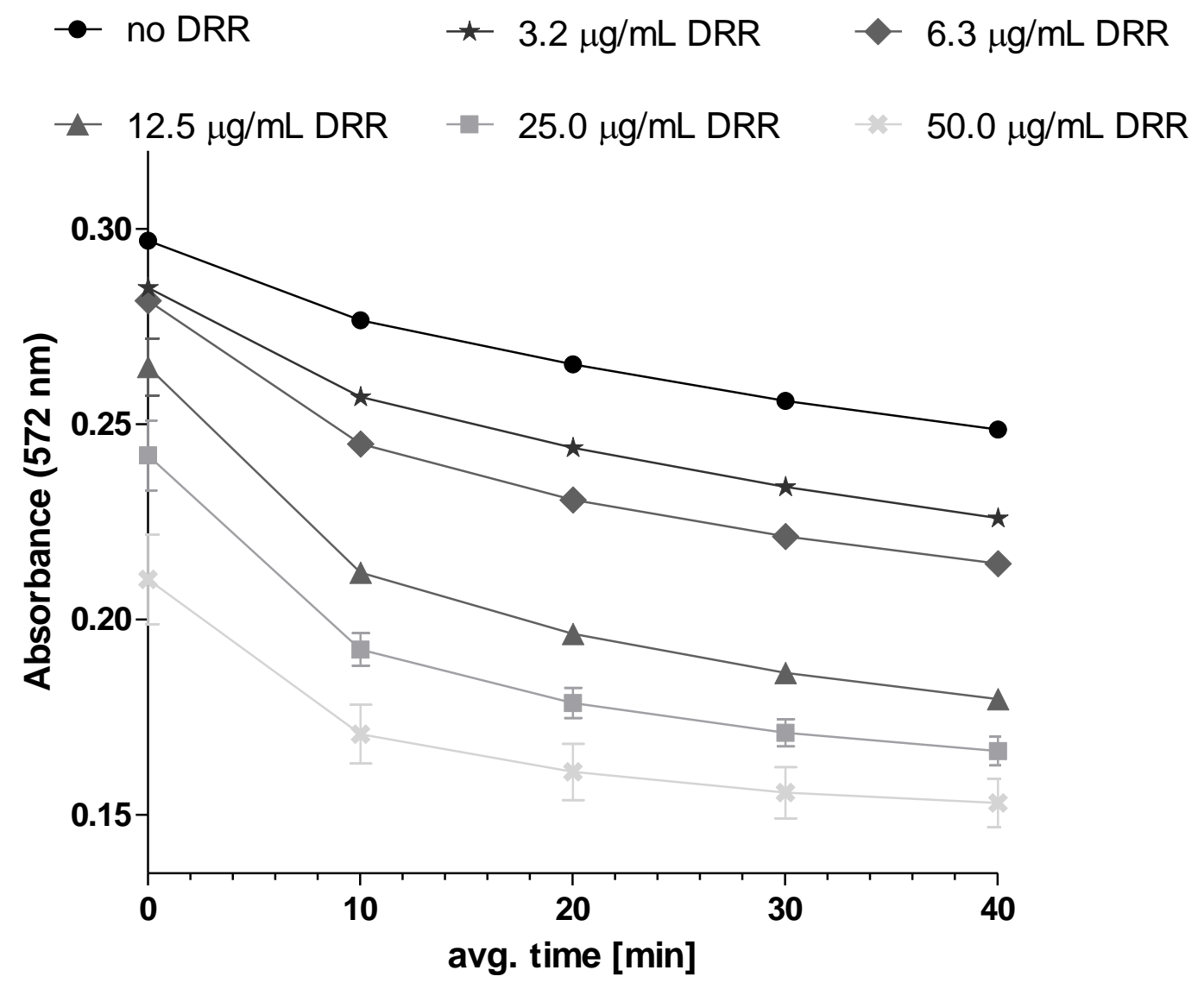

Figure 2. Kinetic absorbance measurements obtained of the cresol red based PLA 2 assay. Concentrations of phosphatidylcholine and cresol red were $0.66 \mathrm{mM}$ and $37 \mu \mathrm{M}$, respectively. Assay was performed in presence of a DRR concentration series with final assay concentrations of $50 \mu \mathrm{g} / \mathrm{mL}$, $25 \mu \mathrm{g} / \mathrm{mL}, 12.5 \mu \mathrm{g} / \mathrm{mL}, 6.3 \mu \mathrm{g} / \mathrm{mL}$ and $3.2 \mu \mathrm{g} / \mathrm{mL}$ (visualized from bottom to top). The absorbance was set at $570 \mathrm{~nm}$. Each curve represents the mean of two measurements and the error bars represent SEMs 
The starting steepness of the declining curve is correlated to the DRR venom concentration and thus the overall activity of $\operatorname{svPLA}_{2} \mathrm{~S}$ present in the assay mixture. Note that the starting point of the kinetic measurement is the moment the plate reader measurement is initiated and thus does not represent the real starting point, which is the moment the assay mix is pipetted to the venom. As can be seen, increasing DRR concentrations resulted in faster declines in absorbance over time (Figure 2). Also, the higher the concentration of DRR the lower the absorbance of the first measured point due to the initial faster enzymatic conversion rates. Therefore, after pipetting the assay mix to a well plate, the assay readout was started directly.

The assay specificity, i.e. determining whether the assay reflects the action of PLA $A_{2} S$ as the cause of the detected acidification, was performed by analyzing DRR venom in presence of the PLA $\mathrm{P}_{2}$ inhibitor varespladib. A recent study by Lewin et al. demonstrated methylvarespladib and varespladib to reduce venom PLA $_{2}$-induced in vivo pathologies.[17] These compounds were shown to be potent inhibitors for a multitude of SVPLA $_{2} \mathrm{~S}$ in vitro. An IC50 value of $0.96 \mu \mathrm{M} \pm 0.04 \mu \mathrm{M}$ was determined for varespladib.[17] As varespladib is a broadrange (non-specific) $\mathrm{PLA}_{2}$ inhibitor, it was anticipated to be able to inhibit the majority of $\mathrm{SVPLA}_{2} \mathrm{~S}$ present in a venom and as such concentration-dependently reduce the hydrolyzation rate of phosphatidylcholine in the assay. The effect of the concentration of varespladib on the activity of DRR (final assay concentration, $12.5 \mu \mathrm{g} / \mathrm{mL}$ ) was determined using a serial dilution series of varespladib in Tris buffer ( $1 \mathrm{mM} ; \mathrm{pH} 8 ; 10 \mu \mathrm{l} /$ well $)$ with final concentrations of 20,2,0.002, and $0 \mu \mathrm{M}$ (Figure 3). 

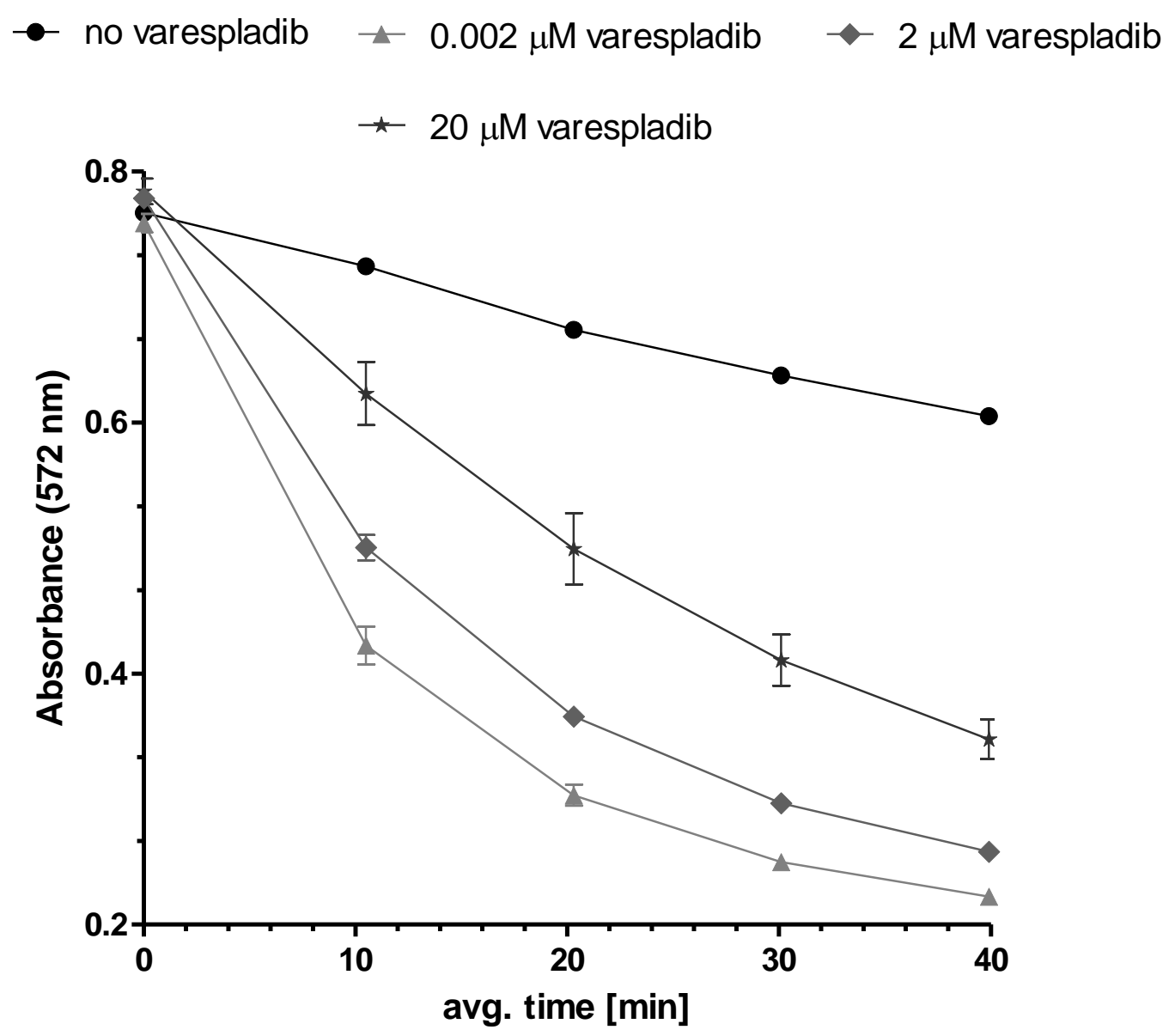

Figure 3: Kinetic absorbance measurements obtained for assessing the inhibitory effect of the PLA inhibitor varespladib on the cresol red based $\mathrm{PLA}_{2}$ assay. Concentrations of phosphatidylcholine, cresol red, and DRR were $0.66 \mathrm{mM}$ and $37 \mu \mathrm{M}$, and $12.5 \mu \mathrm{g} / \mathrm{mL}$, respectively. Assay was performed in presence of varespladib with final concentrations of $20,2,0.002$, and $0 \mu \mathrm{M}$. The absorbance was set at $570 \mathrm{~nm}$. Each curve represents the mean of three measurements and the error bars represent SEMs.

When increasing concentrations of varespladib were added to the assay mixture, a concentration-dependent decrease in $\mathrm{PLA}_{2}$ activity was observed visible as a decrease in steepness of the curves. The highest concentration varespladib tested almost overlapped with the blank measurement (upper curve) clearly showing that the enzymatic acidification of the bioassay mixture was almost fully inhibited at this concentration varespladib. In the blank measurement, a decrease in absorbance was observed due to non-enzymatic (chemical) hydrolysis of phosphatidylcholine. 


\subsection{PLA 2 assay based on fluorescein}

\subsubsection{Assay development}

The fluorescence quantum yield of fluorescein is $\mathrm{pH}$ dependent, being highest at around $\mathrm{pH}$ 8. Its fluorescence decreases in the presence of lowered $\mathrm{pH}$, which is the detection principle of the fluorescence assay format. Below pH 6 the emission starts to get weak, and becomes undetectable at very acidic conditions.[30,31] For this assay a Tris buffer of $\mathrm{pH} 8$ was chosen (as for cresol red) and the decrease of fluorescence intensity of fluorescein was monitored as result of $\mathrm{PLA}_{2}$ activity causing a drop in $\mathrm{pH} .[30,31]$ Additional information and results on the optimization of the fluorescein-based PLA $A_{2}$ activity assay is provided in Section S4 of the supporting information. Different fluorescein concentrations were tested (final concentrations: $0.2,0.5,1.0$, and $5.0 \mu \mathrm{M}$ ). The same phosphatidylcholine concentration as for the cresol red-based assay was used assuming the substrate concentration to be independent of the $\mathrm{pH}$ indicator used. Increasing the fluorescein concentration yielded more intense fluorescence signals at the start of a measurement (see Figure S4 in the supporting information). The optimal fluorescein concentration was determined to be $1 \mu \mathrm{M}$, providing optimal signal-to-noise ratios while achieving acceptable assay repeatability. Concentrations of $1 \mu \mathrm{M}$ fluorescein and $0.66 \mathrm{mM}$ phosphatidylcholine were used for all subsequent experiments.

\subsubsection{Fluorescein PLA 2 assay evaluation}

The optimized fluorescein-based assay was further evaluated for sensitivity and LOD. DRR concentrations of $12.5,6.1,3.0,1.6,0.8$, and $0 \mu \mathrm{g} / \mathrm{mL}$ in Tris buffer $(1 \mathrm{mM} ; \mathrm{pH} 8 ; 10$ $\mu \mathrm{l} /$ well) were analyzed (Figure 4 ). The specificity was again tested by performing the activity assay with DRR in presence of different concentrations of varespladib. 


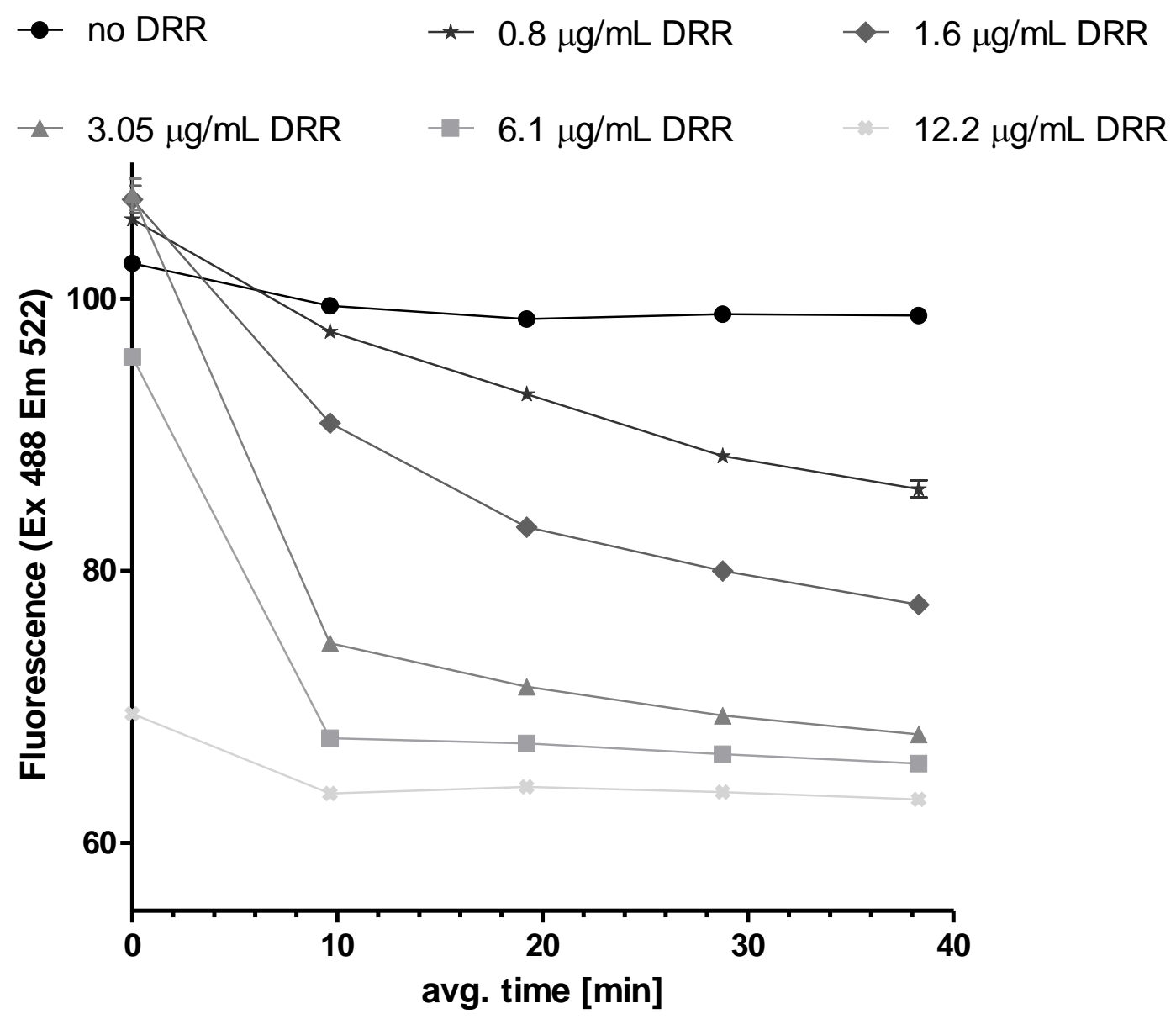

Figure 4: Kinetic fluorescence measurements obtained for the fluorescein based PLA2 assay. Concentrations of phosphatidylcholine and fluorescein were $0.66 \mathrm{mM}$ and $1 \mu \mathrm{M}$, respectively. DRR concentrations tested: $12.5,6.3,3.2,1.6$, and $0.8 \mu \mathrm{g} / \mathrm{mL}$. Fluorescence was measured using an excitation wavelength of $488 \mathrm{~nm}$ and an emission wavelength of $520 \mathrm{~nm}$. Each curve represents the mean of three measurements and the error bars represent SEMs.

The DRR serial dilution series was added to different wells and then vacuum centrifuge dried prior to assay pipetting to avoid undesired dilution effects. As with the previous assay, the starting point of the kinetic measurement is the moment the plate reader measurement is initiated and as such thus not the real starting point, which is the moment the assay mix is pipetted to the venom. Therefore, after pipetting the assay mix to a well plate, the assay readout was started as soon as possible. Increased DRR concentrations resulted in increased progression of the $\operatorname{svPLA}_{2} \mathrm{~S}$ enzymatic activity visible as declined fluorescent intensities observed at the first measurement point of the curves. The last measurement point for the two highest DRR concentrations tested $(12.5 \mu \mathrm{g} / \mathrm{mL}$ and $6.3 \mu \mathrm{g} / \mathrm{mL})$ almost overlapped, indicating a smaller assay window for the fluorescein-based assay as compared 
to the cresol red assay when performing an end-point measurement. The results also show that the fluorescein assay was more sensitive than the cresol red assay for DRR venom. With this assay, clear hydrolyzation was already observed within 10 minutes at a DRR concentration of $1.6 \mu \mathrm{g} / \mathrm{mL}$. In the fluorescein assay, a concentration of $0.8 \mu \mathrm{g} / \mathrm{mL}$ DRR still gave a measurable effect after 40 minutes.

The fluorescein-based assay was then evaluated for specificity for PLA $\mathrm{A}_{2}$ activity by measuring a concentration series of the $\mathrm{PLA}_{2}$ inhibitor varespladib. The effect of the concentration of varespladib on the activity of DRR was determined for two final concentrations of DRR snake venom ( 12.5 and $1.6 \mu \mathrm{g} / \mathrm{mL}$; Figure $5 \& 6$ respectively). The choice to test two DRR concentrations was because $12.5 \mu \mathrm{g} / \mathrm{mL}$ (same concentration as used for the cresol red assay) gave very rapid enzymatic hydrolyzation for this assay. Serial dilution series of varespladib in Tris buffer $(1 \mathrm{mM} ; \mathrm{pH} 8 ; 10 \mu \mathrm{l} /$ well $)$ with final concentrations of $50,5.0,0.5,0.05$, and $0 \mu \mathrm{M}$ were tested (Figures 5 and 6 ). Varespladib was found to inhibit the $\mathrm{PLA}_{2}$ activity in a concentration-dependent manner, with full inhibition observed at a concentration of $5 \mu \mathrm{M}$ for the $12.5 \mu \mathrm{g} / \mathrm{mL}$ DRR experiment and 50 $\mu \mathrm{M}$ for the $1.6 \mu \mathrm{g} / \mathrm{mL}$ DRR experiment. As also observed with the cresol red assay, the fluorescein-based assay thus shows specificity towards enzymatic PLA 2 activity.

To summarize the two approaches compared here, the PLA $A_{2}$ assay using cresol red facilitates measuring a wider range of $\mathrm{PLA}_{2}$ concentrations in comparison with the fluorescein-based assay. However, the latter assay is more sensitive. 
bioRxiv preprint doi: https://doi.org/10.1101/2020.01.20.912758; this version posted January 20, 2020. The copyright holder for this preprint (which was not certified by peer review) is the author/funder, who has granted bioRxiv a license to display the preprint in perpetuity. It is made available under aCC-BY-ND 4.0 International license.

-- no Varespladib \& no DRR

- $0.5 \mu \mathrm{M}$ Varespladib

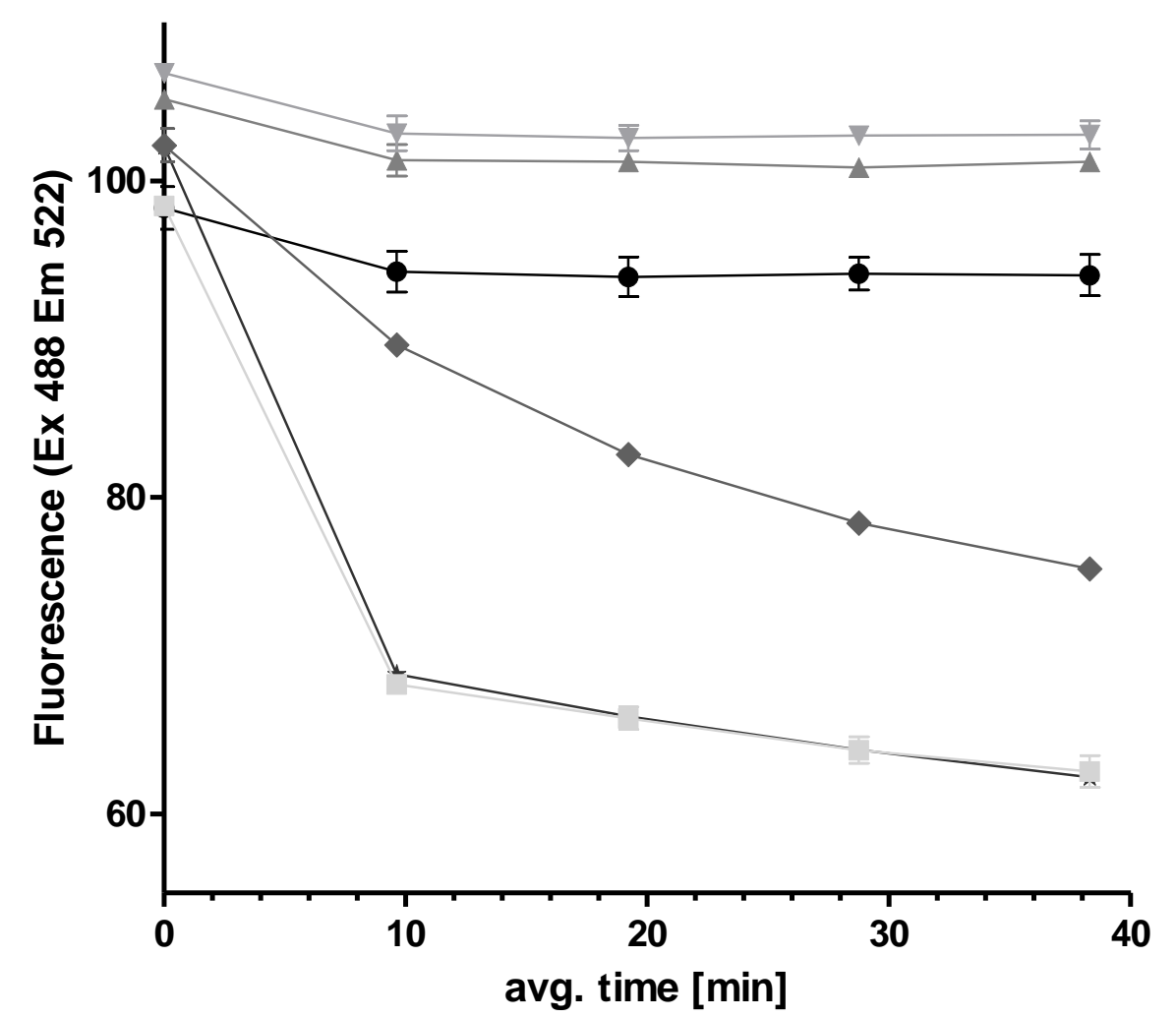

Figure 5: Kinetic fluorescence measurements obtained for assessing the inhibitory effect of the PLA 2 inhibitor varespladib on the fluorescein based $\mathrm{PLA}_{2}$ assay. Concentrations of phosphatidylcholine, fluorescein, and DRR were $0.66 \mathrm{mM}$ and $1 \mu \mathrm{M}$, and $12.5 \mu \mathrm{g} / \mathrm{mL}$, respectively. The assay was performed in presence of varespladib with final concentrations of $50,5.0,0.5,0.05, a n d 0 \mu \mathrm{M}$. Fluorescence was measured using an excitation wavelength of $488 \mathrm{~nm}$ and an emission wavelength of $520 \mathrm{~nm}$. Each curve represents the mean of two measurements and the error bars represent SEMs. 
$\rightarrow$ no Varespladib \& no DRR

$\rightarrow 0.5 \mu \mathrm{M}$ Varespladib no Varespladib

$\neg 5 \mu \mathrm{M}$ Varespladib $\star 0.05 \mu \mathrm{M}$ Varespladib

$\rightarrow 50 \mu \mathrm{M}$ Varespladib

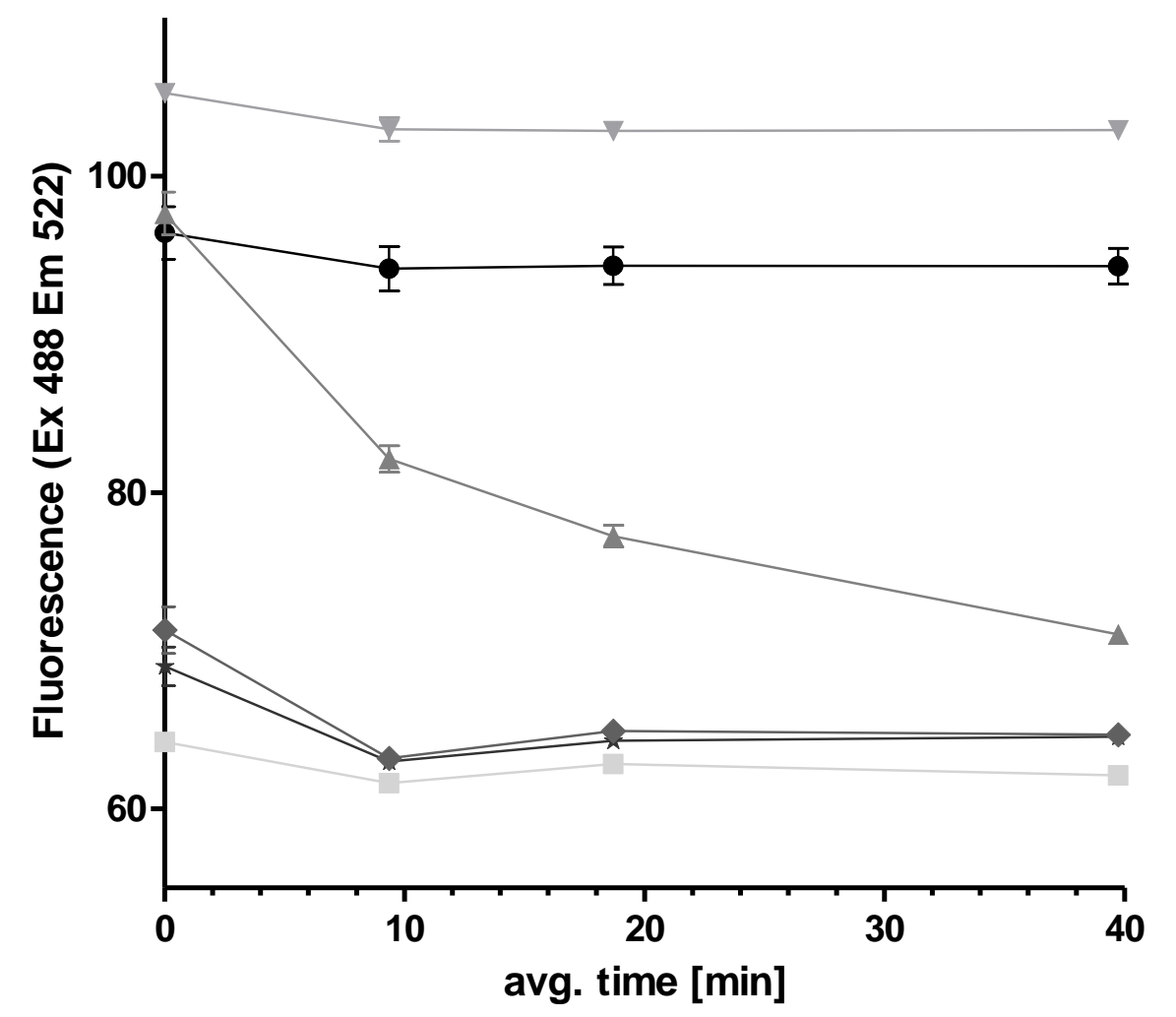

Figure 6: Kinetic fluorescence measurements obtained for assessing the inhibitory effect of the PLA inhibitor varespladib on the fluorescein based $\mathrm{PLA}_{2}$ assay. Concentrations of phosphatidylcholine, fluorescein, and DRR were $0.66 \mathrm{mM}$ and $1 \mu \mathrm{M}$, and $1.6 \mu \mathrm{g} / \mathrm{mL}$, respectively. The assay was performed in presence of varespladib with final concentrations of $50,5.0,0.5,0.05$, and $0 \mu M$. Fluorescence was measured using an excitation wavelength of $488 \mathrm{~nm}$ and an emission wavelength of $520 \mathrm{~nm}$. Each curve represents the mean of two measurements and the error bars represent SEMs. 


\subsection{Coupling of the two PLA 2 assay formats with nanofractionation analytics}

Finally, the two developed assays were incorporated into the nanofractionation analytics platform. This allowed for obtaining bioactive $\mathrm{PLA}_{2}$ profiles of snake venoms after chromatographic separation.

SVPLA $_{2} S$ are derived from members of the SPLA family, which are found in mammals and other vertebrates. It is said that the genes expressing $\operatorname{SVPLA}_{2} \mathrm{~s}$ have undergone gene duplication and accelerated evolution over evolutionary time, which has resulted in structural, functional, and expressional level variations of svPLA ${ }_{2}$ s isoforms.[14,32] As such, many snake venoms are known to contain a number of different svPLA $A_{2}$ isoforms. The presence of these isoforms, and their abundances, can thus vary greatly according to species, but also according to, for example, population, age and sex of a snake, and (prey) ecology.[33-35] The generic svPLA 2 tertiary structure, may contain up to seven disulfide bridges. This means that for an enzyme, $\operatorname{svPLA}_{2} \mathrm{~S}$ are considered to be rather stable and are therefore relatively resistant to heat, organic solvents, and acidic conditions.[17] These properties, their high abundance in many snake venoms, and their relatively low molecular weight ( $\sim 13$ to $15 \mathrm{kDa}$ ) is advantageous for their intact isolation/fractionation using reversed phase liquid chromatography (RPLC) thereby allowing subsequent characterization and bioactivity profiling.[36,37]

The nanofractionation analytics platform connects chromatographic separations of venoms with UV data collection, optionally mass spectrometry, and high-resolution fractionation on well plates followed by bioassaying. This platform for screening snake venoms has been described earlier by others, including for example Mladic et al.[29] and Still et al.[28] for other assay formats. In this study, snake venoms were separated using RP-LC with a post column split directing $90 \%$ of the effluent to a high-resolution fraction collector (e.g. the FractioMate) and $10 \%$ to UV and optionally MS. After fraction collection in 384-well plates, the plates were vacuum centrifuged to remove solvents after which one of

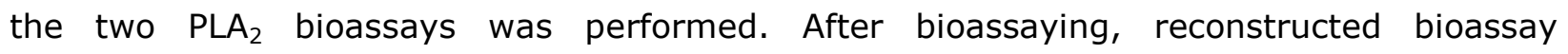
chromatograms were plotted which could then be correlated to UV and MS traces in an effort to identify the enzymatically active SVPLA 2 . 
Venom of six snake species were screened for svPLA 2 activity using the cresol red $\mathrm{PLA}_{2}$ assay and venoms of two snakes were screened using the fluorescein-based PLA 2 assay. The results obtained for the cresol red based assay are shown in Figure 7. Each experiment was performed in duplicate and both the LC-UV spectral data as well as the chromatographic bioactivity profiles (representing the mean of three measurements) are provided. The bioassay chromatograms were constructed by plotting the calculated slopes of each measured svPLA 2 activity curve of each well against fractionation time. As 6-sec fractions were collected, high resolution reconstructed bioassay chromatograms were obtained. svPLA 2 activity is detected as an increase in the slopes of the kinetic measurements and is svPLA 2 concentration-dependent (e.g. as shown in Figure 3). The enzymatic activities of eluted $\mathrm{svPLA}_{2} \mathrm{~S}$ are therefore visible in the reconstructed bioassay chromatograms as positive peaks. Each venom analyzed was found to have its own characteristic fingerprint or signature-like LC-UV chromatogram with corresponding bioactivity chromatogram profile. The results displayed in Figure 7 show that the bioactive peaks for all venoms analyzed eluted in the 15 to 25-minute time frame. Later eluting (nonbioactive) peaks may, although not likely for the relatively stable SVPLA ${ }_{2} \mathrm{~S}$, be denaturized $\mathrm{svPLA}_{2} \mathrm{~s}$ (due to the high organic solvent (i.e. acetonitrile) concentration during elution). As can be seen from the chromatographic PLA 2 bioactivity data, all the snake venoms analyzed show positive svPLA 2 bioactivity peaks, which indicates that all venoms profiled contain at least one, but in most cases multiple, svPLA $_{2} \mathrm{~S}$. 
bioRxiv preprint doi: https://doi.org/10.1101/2020.0120.912758; this version posted January 20,2020. The copyright holder for this preprint (which was not certified by peer review) is the author/funder, who has granted bioRxiv a license to display the preprint in perpetuity. It is made available under aCC-BY-ND 4.0 International license.

7A

\section{Bothrops asper}

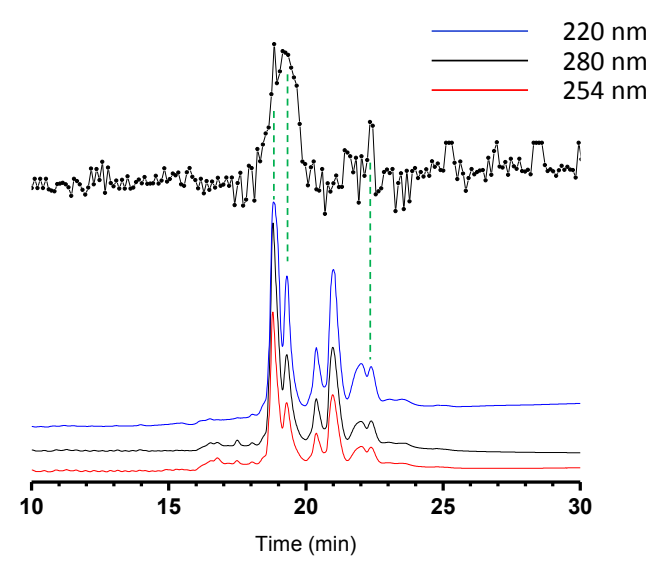

7C

\section{Echis coloratus}

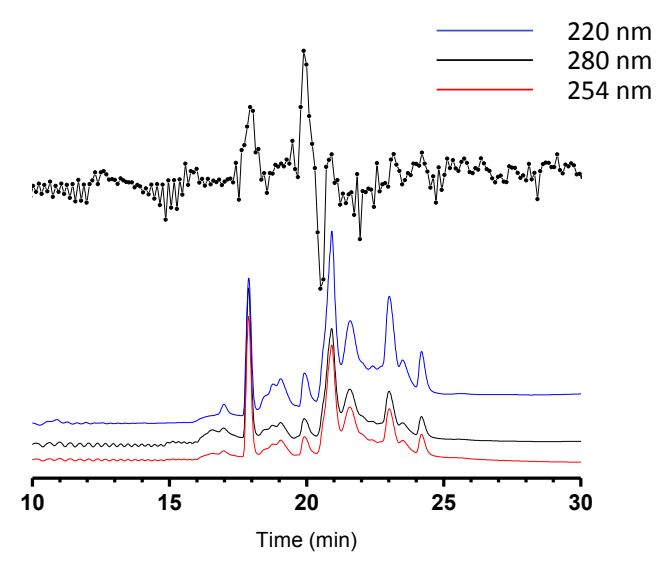

7E

\section{Oxyuranus scutellatus}

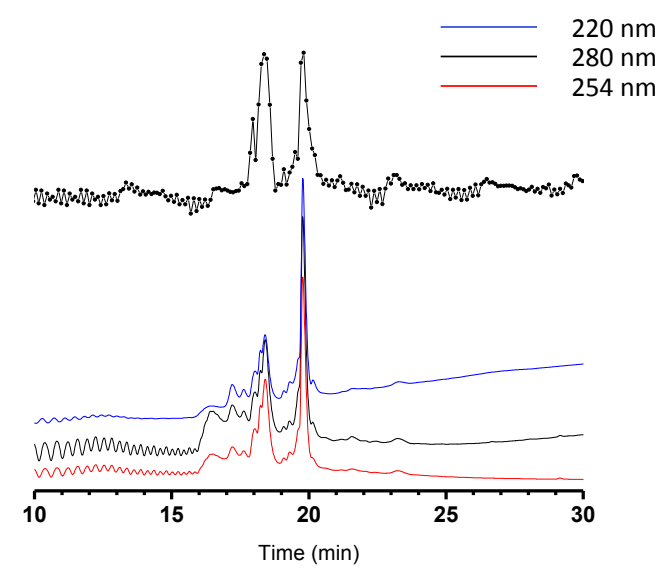

7B

\section{Daboia russelii russelii}

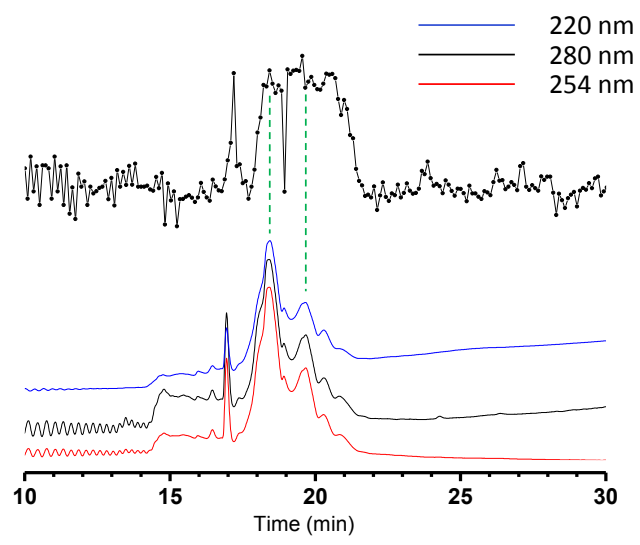

7D

\section{Echis ocellatus}

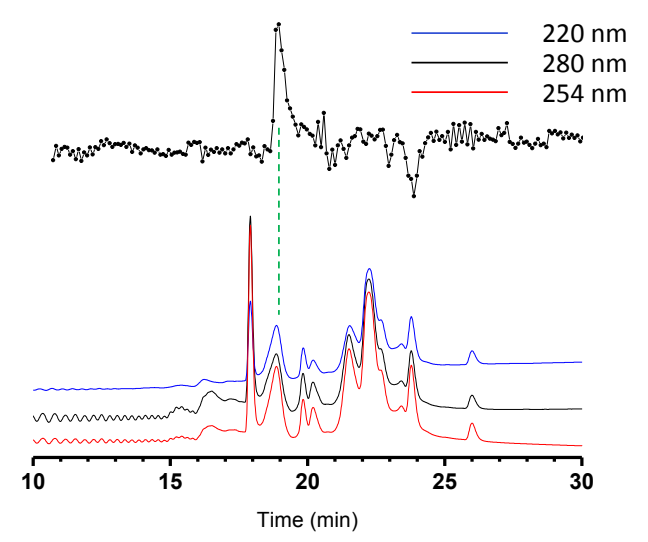

7F

\section{Echis carinatus}

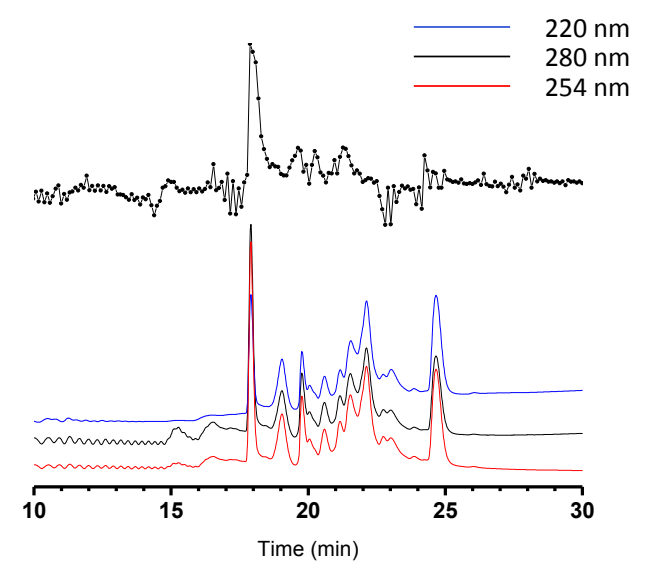


Figure 7: UV-chromatograms measured at three different wavelengths (lower three superimposed chromatograms per figure) and corresponding cresol red assay-PLA 2 reconstructed bioassay chromatograms (upper superimposed chromatograms per figure) obtained from RP-LC separated snake venoms. Snake venoms measured: (a) Bothrops asper; (b) Daboia russelii russelii; (c) Echis coloratus; (d) Echis ocellatus; (e) Oxyuranus scutellatus; (f) Echis carinatus. Experimental conditions: Snake venom concentrations injected were $1 \mathrm{mg} / \mathrm{mL}$ with an injection volume of $50 \mathrm{uL}$. A UV-DAD detector measured the spectrum between 200 and $300 \mathrm{~nm}$ of which $220 \mathrm{~nm}$ (blue), $280 \mathrm{~nm}$ (black) and $254 \mathrm{~nm}$ (red) are plotted in the figures. For correlating bioactivity peaks to tentative toxin identification, the reader is referred to section 3.4 (only for the venoms of Bothrops asper, Daboia russelii russelii, and Echis ocellatus this tentative toxin identification was performed). Green dotted lines indicate tentatively identified SVPLA $_{2} \mathrm{~S}$.

With the fluorescein-based PLA 2 assay, Bothrops asper was profiled (Figure 8). For the fluorescein-based assay it was observed that larger assay windows in combination with lower fluctuation in the baselines were obtained as compared to the cresol red based assay, visualized as positive bioactivity peaks in the fluorescence bioassay chromatograms. For Bothrops asper venom, several SVPLA 2 bioactivities are clearly observed and, when compared to the results obtained from the cresol red assay, additional bioactivities were visualized due to the higher sensitivity of the fluorescein-based assay. After the first set of closely co-eluting svPLA ${ }_{2} \mathrm{~S}$ observed in both assays (between $\sim 17$ to 19 minutes), these additional sVPLA 2 activities are observed after the first broad peak and eluted as one sharp peak followed by two non-baseline separated bioactivity peaks. 


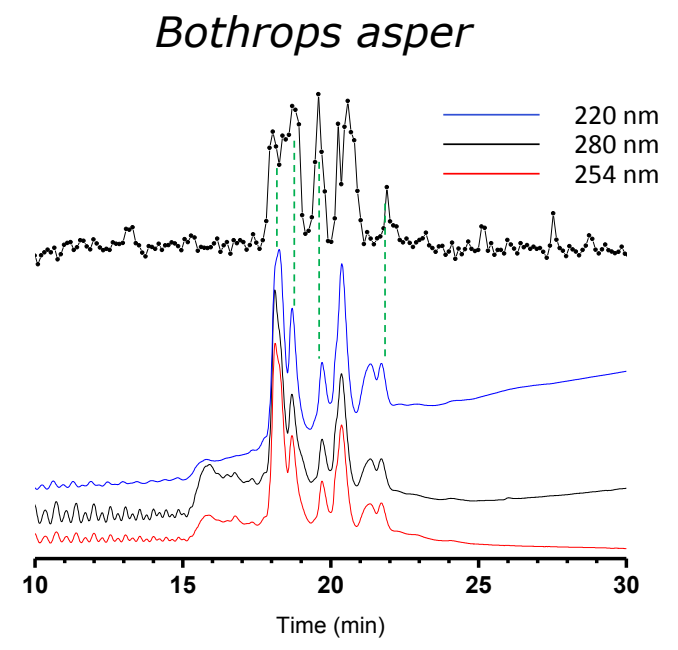

Figure 8: UV-chromatograms measured at three different wavelengths (lower three superimposed chromatograms per figure) and corresponding fluorescein assay-PLA 2 reconstructed bioassay chromatograms (upper superimposed chromatograms per figure) obtained from RP-LC separated snake venoms. Snake venom measured: Bothrops asper; Experimental conditions: Snake venom concentrations injected were $1 \mathrm{mg} / \mathrm{mL}$ with an injection volume of $50 \mu \mathrm{L}$. A UV-DAD detector measured the spectrum between 200 and $300 \mathrm{~nm}$ of which $220 \mathrm{~nm}$ (blue), $280 \mathrm{~nm}$ (black) and 254 $\mathrm{nm}$ (red) are plotted in the figures. For correlating bioactivity peaks to tentative toxin identification, the reader is referred to section 3.4. Green dotted lines indicate tentatively identified SvPLA $\mathrm{A}_{2}$.

It has to be noted that for both assays, not all positive peaks observed need to correspond with SVPLA 2 activities. Although not expected, other toxins in venoms could have enzymatic activities directly or indirectly resulting in acidification or basification of the assay medium. As the assay mixture's color change is dependent on the $\mathrm{pH}$ indicator and therefore the $\mathrm{pH}$ of the mixture, compounds with acidic and/or basic functional groups present in high concentrations could potentially chemically modulate the assay $\mathrm{pH}$ and as such result in negative or positive peaks. Although in general this is not likely to occur, this might be the outcome of the negative peak observed in the bioactivity chromatogram of Echis coloratus (Figure 7C). This negative activity might have resulted from a compound having a basifying effect on the assay mixture's $\mathrm{pH}$. In this specific case it is not expected to have resulted from an activity linked to enzymatic PLA $A_{2}$ activity. In addition, it is known that svPLA $_{2} \mathrm{~S}$ can display a change in activity (mostly an increase) when enzymatically converting higher-ordered lipid aggregate substrates as compared to monomeric substrates.[38] As such, some svPLA 2 may show low activity for the phospholipid substrate used in this study. 


\subsection{Correlation of bioactive peaks with MS and proteomics data for toxin identification}

From literature and the database Uniprot (https://www.uniprot.org/)[39] it was found that all snake venoms profiled in this study have multiple known svPLA ${ }_{2}$. Table 2 displays a summarized list of the number of $\operatorname{svPLA}_{2} \mathrm{~S}$ found in the literature and from the

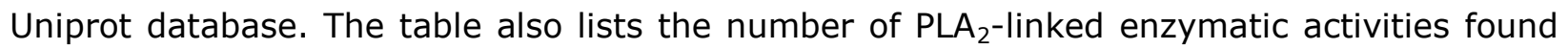
for both assays developed and applied in this study after nanofractionation of the profiled venoms. From the overview it is evident that for most snake venoms analyzed, more individual SVPLA 2 isoforms are reported in the literature and Uniprot, when compared to the number of individual positive peaks found per venom in this study. The reason for this is likely as follows: firstly, snake venoms of the same species, but from different geographical origins, often have different venom compositions implying that not all $\operatorname{SVPLA}_{2} s$ necessarily will be expressed at significant levels in each venom. Secondly, the chromatographic overlap of svPLA $_{2}$ isoforms resulting from chromatographic co-elution of (especially structurally similar) SVPLA$_{2} S$ results in overlapping bioactivity peaks for which multiple $\mathrm{SvPLA}_{2}$ isoforms can be assigned to. This was also clearly shown in other studies by Still et al.[19] and Slagboom et al.[40] In addition, some svPLA $_{2} s$ in Uniprot could be present in a given venom but showed reduced catalytic activity or have lost their activity due to denaturation in our experiments. Furthermore, some sub-classes of svPLA $\mathrm{S}_{2}$ have lost their enzymatic activity (among which are neurotoxic svPLA ${ }_{2} \mathrm{~s}$ and lysine/serine $49 \mathrm{svPLA}_{2} \mathrm{~s}$ ) and/or only have minor enzymatic activity as compared to their other biological functions which can include specific target-binding, chaperoning, and/or membrane-disrupting functions.[13]

Accurate mass measurements and proteomics data of the toxins present in several snake venoms included in this study were recently reported by Slagboom et al.[40] They used the same LC-nanofractionation platform in combination with parallel acquired MS data and profiled coagulopathic activity followed by proteomic characterization of the active coagulopathic compounds. The following three snake venoms analyzed by Slagboom et al were also investigated in this study: Bothrops asper, Echis Ocellatus, and Daboia russelii russelii. The MS and proteomics data of Slagboom et al. was used here for correlation of SVPLA $_{2}$ bioactivity to hypothetical toxin identification in order to determine platform applicability for svPLA 2 profiling of snake venoms towards identification of the bioactives. Slagboom et al. profiled and tentatively identified venom toxins that exhibited coagulopathic activity and thus might not match SvPLA $_{2}$ activities measured this study. Several positive signals in our SVPLA 2 assays could, however, be correlated to identified $S V P L A_{2} s$ by 
Slagboom et al., as they fell within the same retention timeframes (note that the same chromatographic conditions were used in both studies). In Bothrops asper, Slagboom et al. found four svPLA $\mathrm{S}_{2}$ with $\mathrm{m} / \mathrm{z}$-values of $1378.3697^{10+}, 1373.3688^{10+}, 1267.7906^{11+}$, and $1164.8881^{12+}$. Combining the fluorescein and cresol red $\mathrm{PLA}_{2}$ assay data of Bothrops asper measured this study after nanofractionation resulted in correlation of most activities with the MS and proteomics data from Slagboom et al. The first two eluting $\operatorname{svPLA}_{2} \mathrm{~s}$ with $\mathrm{m} / \mathrm{z}^{-}$ values of $1378.3697^{10+}$ and $1373.3688^{10+}$ co-eluted in the chromatogram and therefore could not be differentiated. Two additional activities were detected in the fluorescent PLA $A_{2}$ assay, which were not measured by Slagboom et al (who only did MS and proteomics analysis on

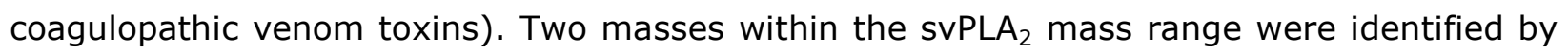
Slagboom et al for Daboia russelii russelii venom and one for Echis ocellatus venom. For both venoms, the identified $\mathrm{m} / \mathrm{z}$-values could be correlated to the SVPLA $\mathrm{A}_{2}$ bioactivity peaks falling within the same retention timeframe and were $1511.6962^{9+}$ and $1518.5946^{9+}$ for Daboia russelii russelii venom, and $1537.0489^{9+}$ for Echis ocellatus venom. In Figure 7 and Figure 8 , the tentatively identified $\mathrm{SVPLA}_{2} \mathrm{~S}$ correlating to bioactivity peaks are indicated with green marker arrows pointing to their respective bioactivity peaks for Bothrops asper, Echis ocellatus, and Daboia russelii russelii venoms.

Table 2: Overview of numbers of svPLA 2 isoforms identified by different research groups and placed in the Uniprot database, numbers of SVPLA 2 isoforms identified by Slagboom et al, and detected number of bioactives in the developed cresol red and/or fluorescein-based PLA ${ }_{2}$ assays described in this study. n.d. means no data available.

\begin{tabular}{|l|c|c|c|c|}
\hline Snake species & $\begin{array}{l}\text { Uniprot } \\
\text { database svPLA }\end{array}$ & $\begin{array}{l}\text { Masses of svPLA } \\
\text { isoforms }\end{array}$ & $\begin{array}{l}\text { svPLA }_{2} \text { bioactivities } \\
\text { found in cresol red } \\
\text { Slagboom et al }\end{array}$ & $\begin{array}{l}\text { svPLA }_{2} \text { bioactivities } \\
\text { found in fluorescein }_{2} \text { assay }\end{array}$ \\
\hline Bothrops asper & 6 & 4 & 2 & 6 \\
\hline Daboia russelii russelii & $\sim 33$ & 2 & $\mathrm{n}>3$ & n.d. \\
\hline Echis coloratus & 10 & n.d. & $2-3$ & n.d. \\
\hline Echis ocellatus & 1 & 2 & $2-5$ & n.d. \\
\hline Oxyuranus scutellatus & 12 & 0 & 1 & n.d. \\
\hline Echis carinatus & 6 & n.d. & n.d. \\
\hline
\end{tabular}




\section{Conclusion}

The PLA 2 assays developed herein were demonstrated to be sensitive and robust and were successfully coupled to nanofractionation analytics to analyze SVPLA 2 activity of separated venom toxins. The PLA 2 assay using cresol red was found to have the largest assay window, i.e. being able to detect a larger variation in $\mathrm{PLA}_{2}$ concentrations, while the fluoresceinbased assay proved to be the most sensitive assay, thereby making both assays complementary to one another. When using C18 RP-LC with nanofractionation analytics for $\mathrm{SVPLA}_{2}$ profiling of snake venoms, reproducible specific fingerprint-like separation profiles were obtained of which bioactive $\operatorname{SVPLA}_{2} \mathrm{~S}$ showed positive bioactivity peaks in the reconstructed bioactivity chromatograms. As many SVPLA $_{2} \mathrm{~S}$ have similar primary sequences, and thus much structural resemblance, overlap of different bioactive svPLA ${ }_{2} \mathrm{~S}$ by co-elution was expected and was indeed observed in this study. Prior accurate mass and proteomics data of some of the venoms used in this study was repurposed here for $\operatorname{svPLA}_{2}$ identification, and to assess assay and analytical platform performance, resulting in bioactivity chromatograms with tentatively identified enzymatically active SVPLA $\mathrm{A}_{2}$. We anticipate that our development of new analytics for rapidly profiling SVPLA 2 activity will have utility for future research on snakebite pathologies caused by SVPLA 2 toxins, and for the identification of novel inhibitory molecules capable of neutralizing $\operatorname{SVPLA}_{2} S$ for their future selection and translation into snakebite therapeutics.

\section{Acknowledgements}

This study was supported by: (i) a Sir Henry Dale Fellowship to N.R.C.736 (200517/Z/16/Z) jointly funded by the Wellcome Trust and Royal Society, and (ii) a China Scholarship Council (CSC) fellowship to C.X. 


\section{References}

[1] M. Murakami, Y. Taketomi, Y. Miki, H. Sato, T. Hirabayashi, K. Yamamoto, Recent progress in phospholipase $\mathrm{A} 2$ research: From cells to animals to humans, Prog. Lipid Res. 50 (2011) 152-192. doi:10.1016/j.plipres.2010.12.001.

[2] E.A. Dennis, J. Cao, Y.H. Hsu, V. Magrioti, G. Kokotos, Phospholipase A2 enzymes: Physical structure, biological function, disease implication, chemical inhibition, and therapeutic intervention, Chem. Rev. 111 (2011) 6130-6185. doi: $10.1021 / c r 200085 w$.

[3] N. sastry Yarla, K. Satyakumar, D. Srinivasu, K. DSVGK, Phospholipase A2: A Potential Therapeutic Target in Inflammation and Cancer (In silico, In vitro, In vivo and Clinical Approach), J. Cancer Sci. Ther. 07 (2015) 249-252. doi:10.4172/19485956.1000357.

[4] M. Murakami, Y. Taketomi, Y. Miki, H. Sato, K. Yamamoto, G. Lambeau, Emerging roles of secreted phospholipase A2 enzymes: The 3rd edition, Biochimie. (2014) 105113. doi:10.1016/j.biochi.2014.09.003.

[5] V. Brglez, G. Lambeau, T. Petan, Secreted phospholipases A2 in cancer: Diverse mechanisms of action, Biochimie. (2014) 114-123. doi:10.1016/j.biochi.2014.09.023.

[6] T. Tasoulis, G.K. Isbister, A review and database of snake venom proteomes, Toxins (Basel). 9 (2017). doi:10.3390/toxins9090290.

[7] C.R. Ferraz, A. Arrahman, C. Xie, N.R. Casewell, R.J. Lewis, J. Kool, F.C. Cardoso, Multifunctional Toxins in Snake Venoms and Therapeutic Implications: From Pain to Hemorrhage and Necrosis, Front. Ecol. Evol. 7 (2019) 1-19. doi: 10.3389/fevo.2019.00218.

[8] I. Panfoli, D. Calzia, S. Ravera, A. Morelli, Inhibition of hemorragic snake venom components: Old and new approaches, Toxins (Basel). 2 (2010) 417-427. doi: $10.3390 /$ toxins 2040417.

[9] World Health Organization, http://www.who.int/neglected_diseases/news/Snakebiteenvenoming-mandate-global-action/en/., (2018).

[10] J.M. Gutiérrez, J.J. Calvete, A.G. Habib, R.A. Harrison, D.J. Williams, D.A. Warrell, Snakebite envenoming, Nat. Rev. Dis. Prim. 3 (2017). doi:10.1038/nrdp.2017.63.

[11] R.A. Haney, T. Matte, F.A.S. Forsyth, J.E. Garb, Alternative transcription at venom genes and its role as a complementary mechanism for the generation of venom complexity in the common house spider, Front. Ecol. Evol. 7 (2019) 1-13. doi: 10.3389/fevo.2019.00085.

[12] N.R. Casewell, S.C. Wagstaff, W. Wuster, D.A.N. Cook, F.M.S. Bolton, S.I. King, D. Pla, L. Sanz, J.J. Calvete, R.A. Harrison, Medically important differences in snake venom composition are dictated by distinct postgenomic mechanisms, Proc. Natl. Acad. Sci. U. S. A. 111 (2014) 9205-9210. doi:10.1073/pnas.1405484111.

[13] P. Gopalakrishnakone, J.J. Calvete, Venom Genomics and Proteomics, 2016. doi: 10.1007/978-94-007-6416-3. 
[14] J.J. Calvete, Snake venomics at the crossroads between ecological and clinical toxinology, Biochem. (Lond). 41 (2019) 28-33. doi:10.1042/bio04106028.

[15] S. Ainsworth, J. Slagboom, N. Alomran, D. Pla, Y. Alhamdi, S.I. King, F.M.S. Bolton, J.M. Gutiérrez, F.J. Vonk, C.-H. Toh, J.J. Calvete, J. Kool, R.A. Harrison, N.R. Casewell, The paraspecific neutralisation of snake venom induced coagulopathy by antivenoms, Commun. Biol. 1 (2018) 34. doi:10.1038/s42003-018-0039-1.

[16] L.-O. Albulescu, M. Hale, S. Ainsworth, J. Alsolaiss, E. Crittenden, J.J. Calvete, M.C. Wilkinson, R.A. Harrison, J. Kool, N.R. Casewell, Preclinical validation of a repurposed metal chelator as a community-based therapeutic for hemotoxic snakebite, BioRxiv. (2019) 717280. doi:10.1101/717280.

[17] M. Lewin, S. Samuel, J. Merkel, P. Bickler, Varespladib (LY315920) appears to be a potent, broad-spectrum, inhibitor of snake venom phospholipase A2 and a possible pre-referral treatment for envenomation, Toxins (Basel). 248 (2016). doi: $10.3390 /$ toxins 8090248 .

[18] N. Petrovic, C. Grove, P.E. Langton, N.L. Misso, P.J. Thompson, A simple assay for a human serum phospholipase A2 that is associated with high-density lipoproteins., J. Lipid Res. 42 (2001) 1706-13. http://www.ncbi.nlm.nih.gov/pubmed/11590228.

[19] O. Sharko, M. Kisel, 1-Acyl-2-[N-(2,4-dinitrophenyl)aminopropionyl]-sn-glycero-3phosphocholine as a chromogenic substrate for phospholipase A2 assay, Anal. Biochem. 413 (2011) 69-71. doi:10.1016/j.ab.2011.02.018.

[20] J. Aufenanger, W. Zimmer, R. Kattermann, Characteristics and clinical application of a radiometric Escherichia coli-based phospholipase A2 assay modified for serum analysis, Clin. Chem. 39 (1993) 605-613.

[21] M. Katsumata, C. Gupta, A.S. Goldman, A rapid assay for activity of phospholipase A2 using radioactive substrate, Anal. Biochem. 154 (1986) 676-681. doi:10.1016/00032697(86)90046-1.

[22] A.L. Darrow, M.W. Olson, H. Xin, S.L. Burke, C. Smith, C. Schalk-Hihi, R. Williams, S.S. Bayoumy, I.C. Deckman, M.J. Todd, B.P. Damiano, M.A. Connelly, A novel fluorogenic substrate for the measurement of endothelial lipase activity, J. Lipid Res. 52 (2011) 374-382. doi:10.1194/jlr.d007971.

[23] L.J. Mitnaul, J. Tian, C. Burton, M.-H. Lam, Y. Zhu, S.H. Olson, J.E. Schneeweis, P. Zuck, S. Pandit, M. Anderson, M.M. Maletic, S.T. Waddell, S.D. Wright, C.P. Sparrow, E.G. Lund, Fluorogenic substrates for high-throughput measurements of endothelial lipase activity, J. Lipid Res. 48 (2007) 472-482. doi:10.1194/jlr.d600041-jlr200.

[24] M. de los A. Camacho-Ruiz, J.C. Mateos-Díaz, F. Carrière, J.A. Rodriguez, A broad pH range indicator-based spectrophotometric assay for true lipases using tributyrin and tricaprylin, J. Lipid Res. 56 (2015) 1057-1067. doi:10.1194/j|r.D052837.

[25] P. Sutto-Ortiz, M. de los A. Camacho-Ruiz, M.R. Kirchmayr, R.M. Camacho-Ruiz, J.C. Mateos-Díaz, A. Noiriel, F. Carrière, A. Abousalham, J.A. Rodríguez, Screening of phospholipase A activity and its production by new actinomycete strains cultivated by solid-state fermentation, Peer]. 5 (2017) e3524. doi:10.7717/peerj.3524.

[26] J.A. Price, A colorimetric assay for measuring phospholipase A2 degradation of phosphatidylcholine at physiological pH, J. Biochem. Biophys. Methods. 70 (2007) 441-444. doi:10.1016/j.jbbm.2006.10.008. 
[27] A.L. de Araújo, F. Radvanyi, Determination of phospholipase A2 activity by a colorimetric assay using a pH indicator, Toxicon. 25 (1987) 1181-1188.

doi:10.1016/0041-0101(87)90136-X.

[28] K.B.M. Still, R.S.S. Nandlal, J. Slagboom, G.W. Somsen, N.R. Casewell, J. Kool, Multipurpose HTS coagulation analysis: Assay development and assessment of coagulopathic snake venoms, Toxins (Basel). 9 (2017) 1-16.

doi: $10.3390 /$ toxins9120382.

[29] M. Mladic, B.M. Zietek, J.K. Iyer, et al., At-line nanofractionation with parallel mass spectrometry and bioactivity assessment for the rapid screening of thrombin and factor Xa inhibitors in snake venoms, Toxicon. 110 (2016) 79-89. doi: 10.1016/j.toxicon.2015.12.008.

[30] M.M. Martin, L. Lindqvist, The $\mathrm{pH}$ dependence of fluorescein fluorescence, J. Lumin. 10 (1975) 381-390.

[31] M.J. Doughty, PH dependent spectral properties of sodium fluorescein ophthalmic solutions revisited, Ophthalmic Physiol. Opt. 30 (2010) 167-174. doi:10.1111/j.14751313.2009.00703.x.

[32] J. Calvete, Venom Genomics and Proteomics, (2016). doi:10.1007/978-94-007-64163.

[33] H.L. Gibbs, W. Rossiter, Rapid evolution by positive selection and gene gain and loss: PLA 2 venom genes in closely related Sistrurus rattlesnakes with divergent diets, J. Mol. Evol. 66 (2008) 151-166. doi:10.1007/s00239-008-9067-7.

[34] I.-H. TSAI, Y.-M. WANG, Y.-H. CHEN, T.-S. TSAI, M.-C. TU, Venom phospholipases A2 of bamboo viper (Trimeresurus stejnegeri): molecular characterization, geographic variations and evidence of multiple ancestries, Biochem. J. 377 (2004) 215-223. doi:10.1042/bj20030818.

[35] I.H. Tsai, H.Y. Tsai, A. Saha, A. Gomes, Sequences, geographic variations and molecular phylogeny of venom phospholipases and threefinger toxins of eastern India Bungarus fasciatus and kinetic analyses of its Pro31 phospholipases A2, FEBS J. 274 (2007) 512-525. doi:10.1111/j.1742-4658.2006.05598.x.

[36] J.M. Gutiérrez, B. Lomonte, Phospholipases A2: Unveiling the secrets of a functionally versatile group of snake venom toxins, Toxicon. 62 (2013) 27-39. doi: $10.1016 /$ j.toxicon.2012.09.006.

[37] S.E. Gasanov, Snake Venom Cytotoxins, Phospholipase A2s, and Zn2+-dependent Metalloproteinases: Mechanisms of Action and Pharmacological Relevance, J. Clin. Toxicol. 4 (2014). doi:10.4172/2161-0495.1000181.

[38] W. Cho, A.G. Tomasselli, R.L. Heinrikson, F.J. Kézdy, The chemical basis for interfacial activation of monomeric phospholipase A2, J. Biol. Chem. 263 (1988) 11237-11241.

[39] https://www.uniprot.org/, (n.d.).

[40] J. Slagboom, M. Mladić, C. Xie, F. Vonk, G.W. Somsen, High throughput screening and identification of coagulopathic snake venom proteins and peptides using nanofractionation and proteomics approaches, BioRxiv. (2019). doi:http://dx.doi.org/10.1101/780155. 


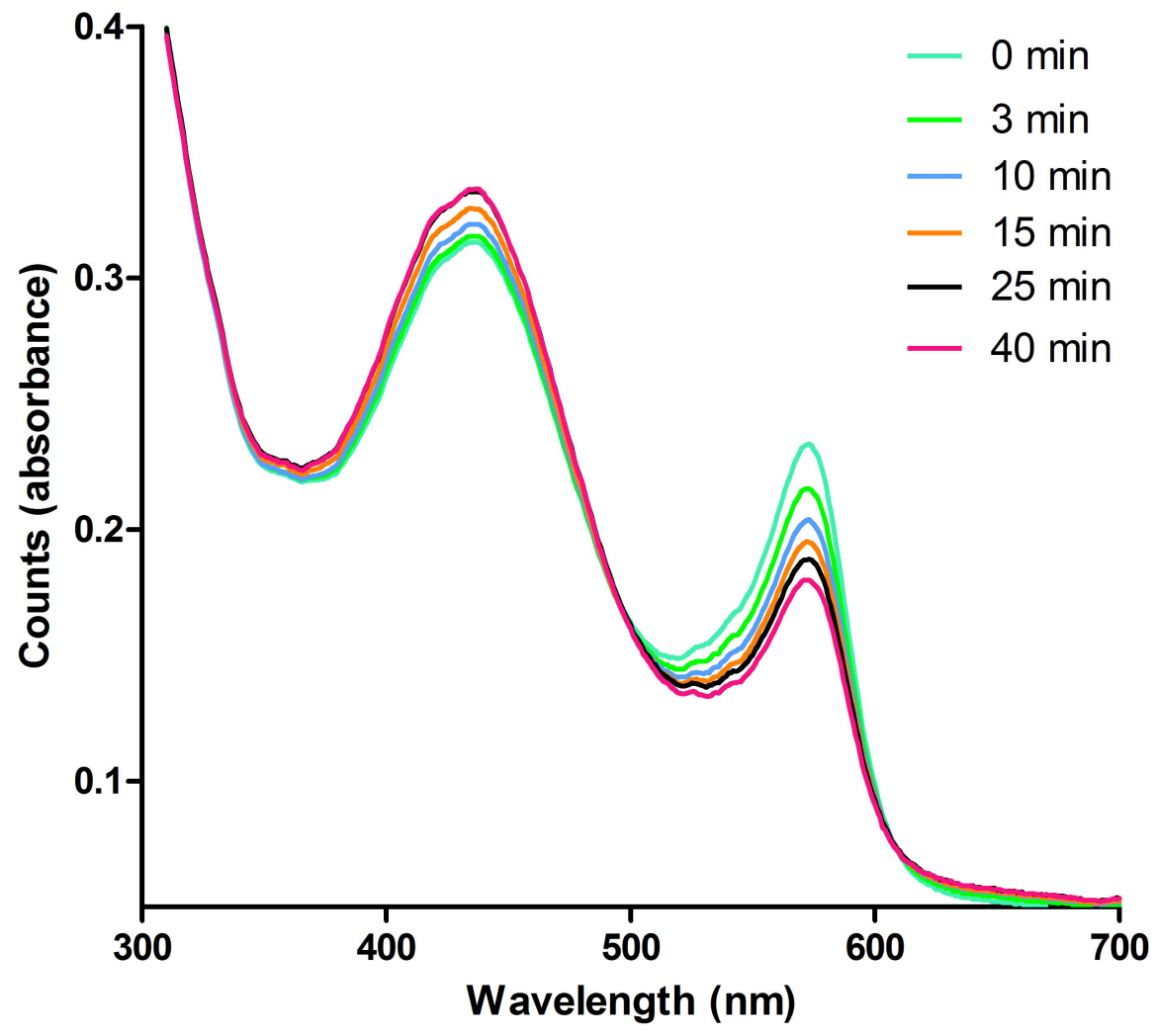


$\bullet$ no DRR

$\pm 12.5 \mu \mathrm{g} / \mathrm{mL}$ DRR $\quad-25.0 \mu \mathrm{g} / \mathrm{mL}$ DRR

* $3.2 \mu \mathrm{g} / \mathrm{mL}$ DRR

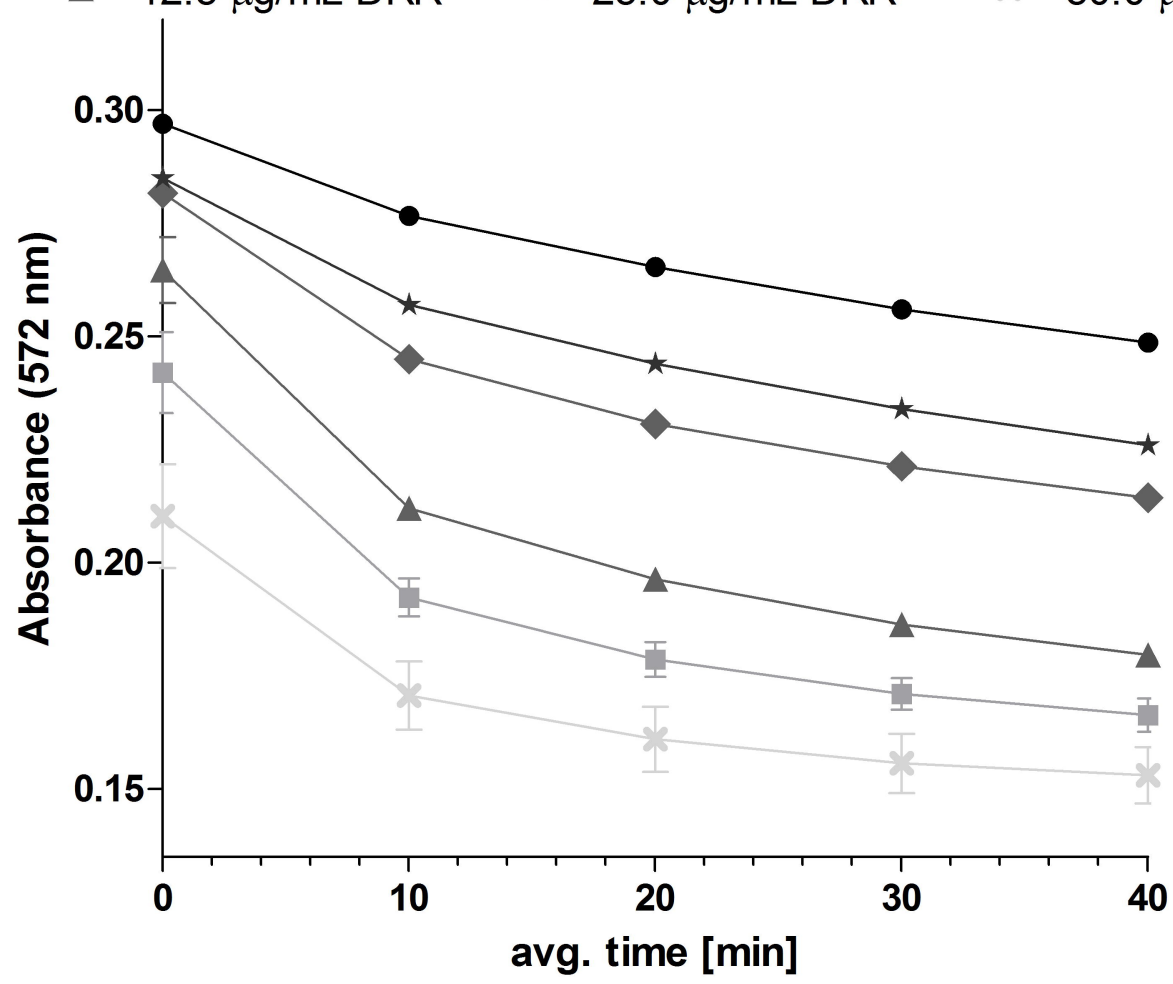




\section{$\star 20 \mu \mathrm{M}$ varespladib}

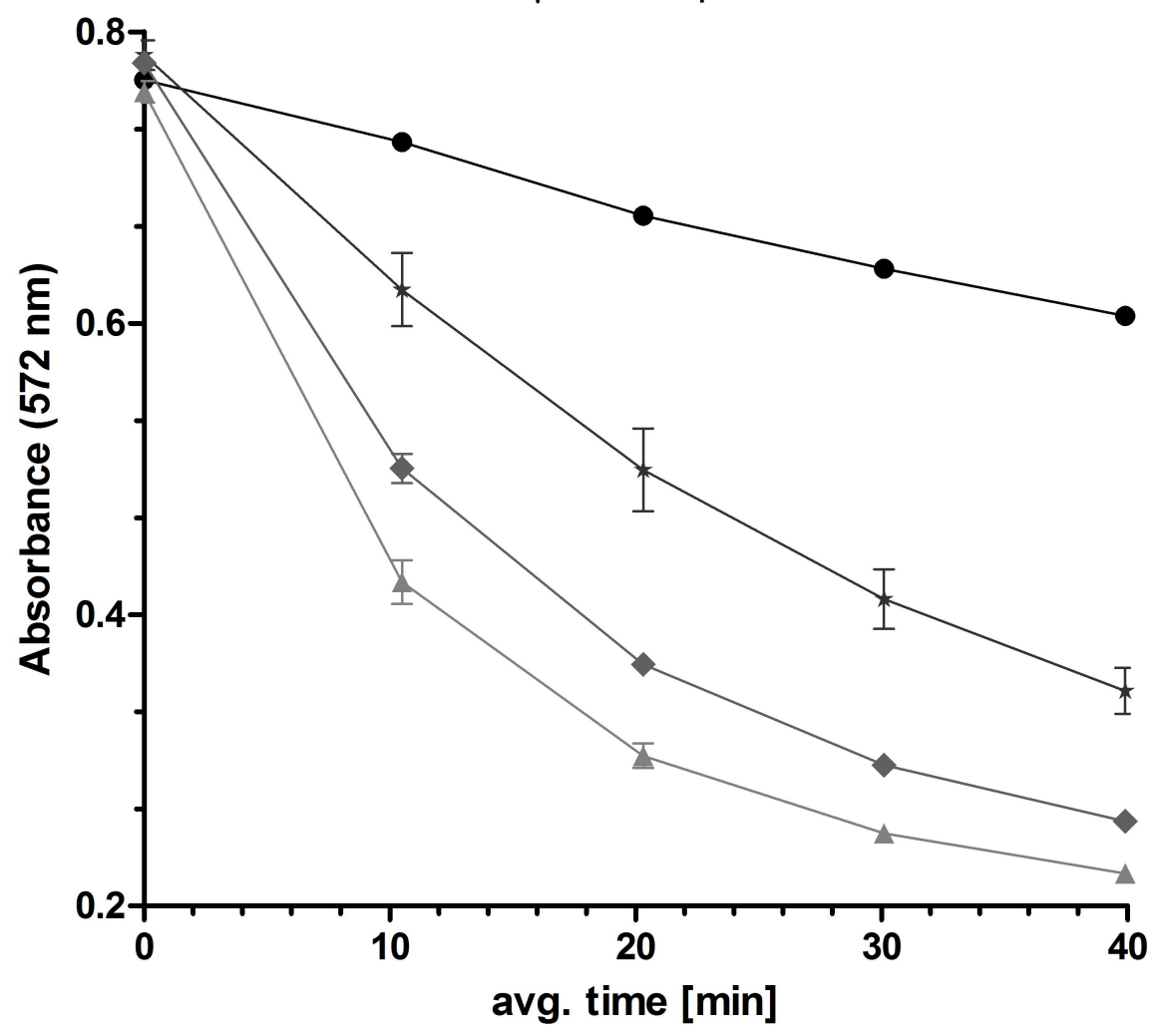


$\rightarrow$ no DRR

$-3.05 \mu \mathrm{g} / \mathrm{mL}$ DRR

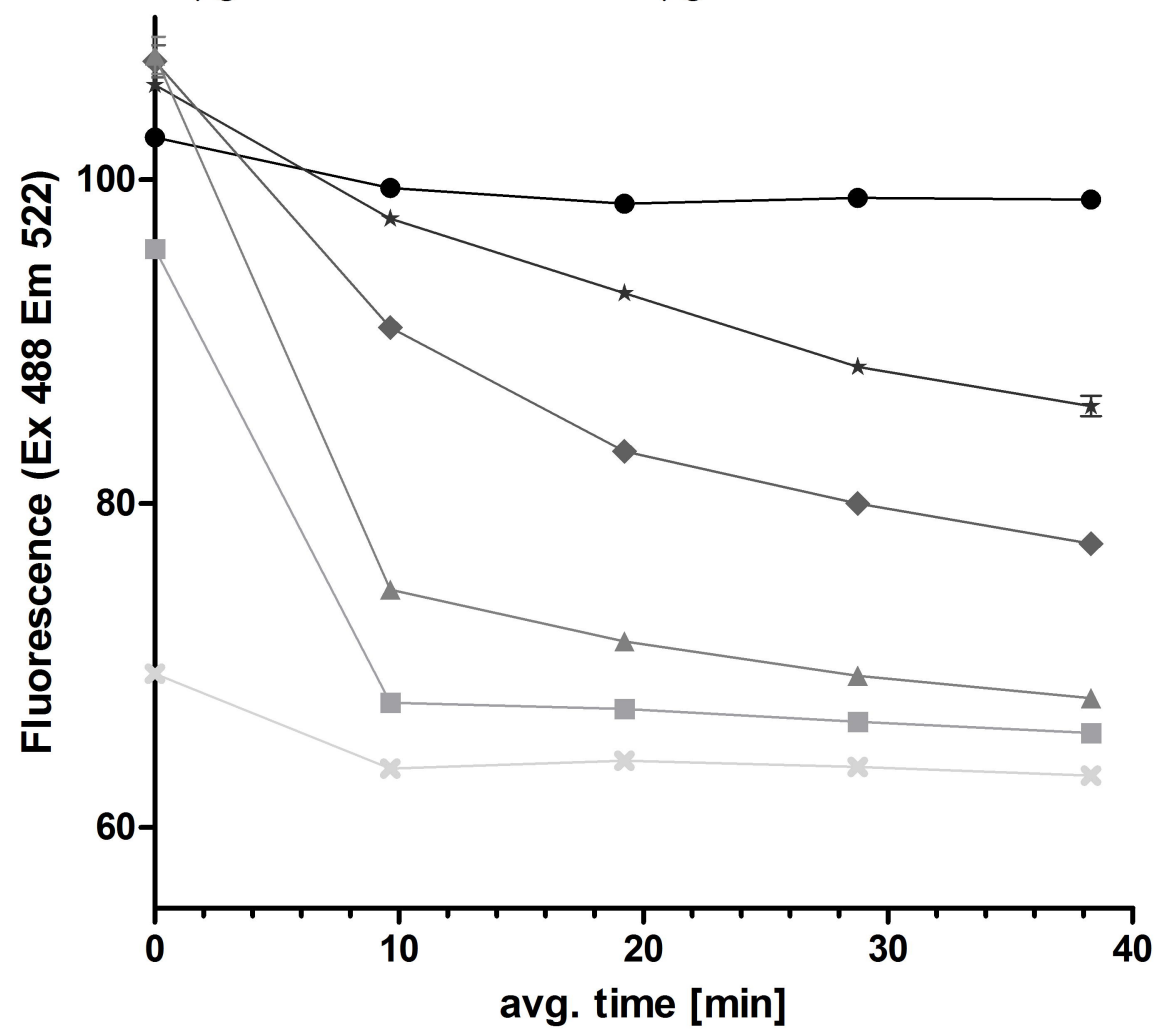


- no Varespladib \& no DRR

$\rightarrow 0.5 \mu \mathrm{M}$ Varespladib

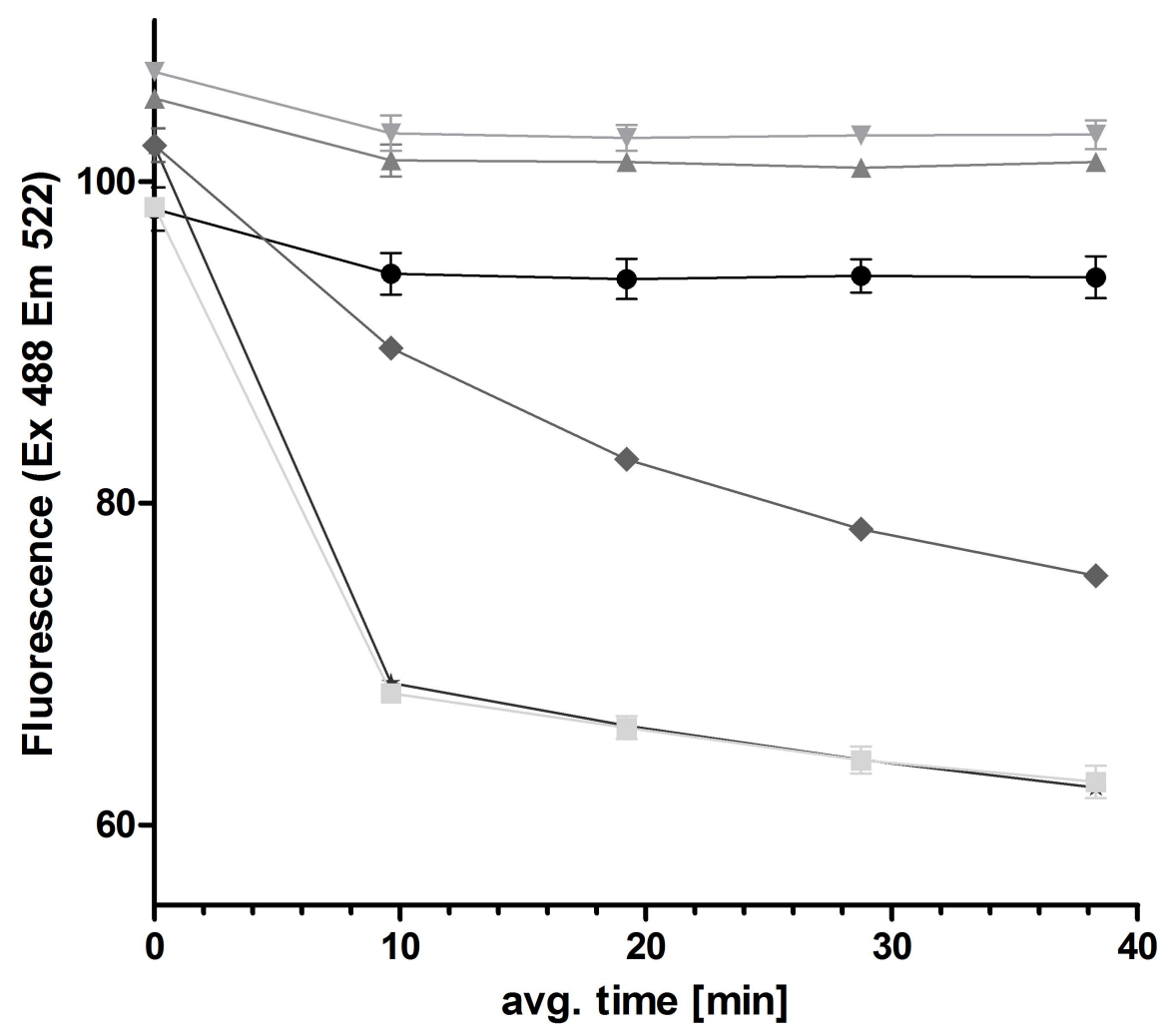


-- no Varespladib \& no DRR

$\checkmark 0.5 \mu \mathrm{M}$ Varespladib no Varespladib

$-5 \mu \mathrm{M}$ Varespladib $\star 0.05 \mu \mathrm{M}$ Varespladib

$\rightarrow 50 \mu \mathrm{M}$ Varespladib

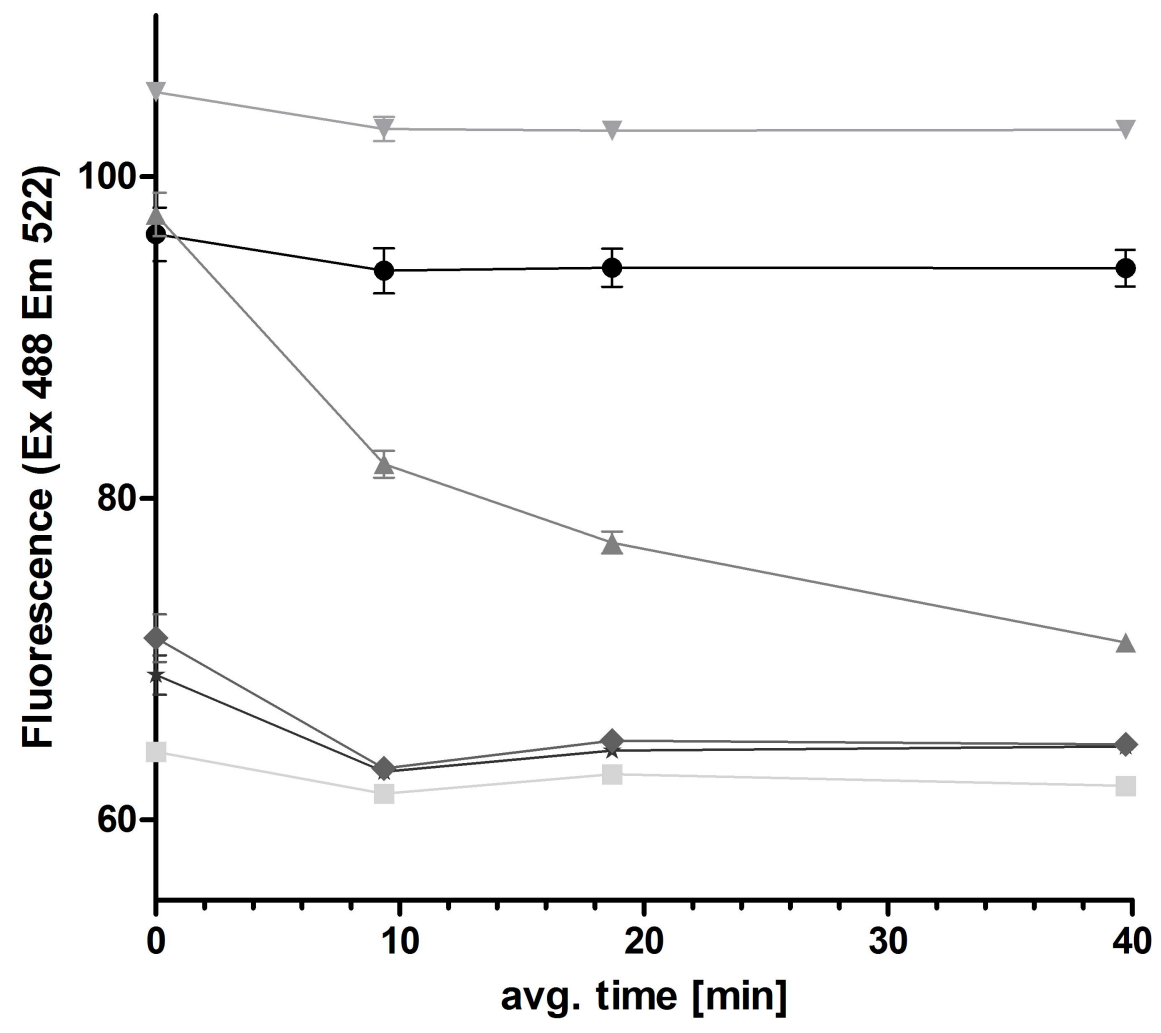


bioRxiv preprint doi: https://doi.org/10.1101/2020.01.20.912758; this version posted January 20, 2020. The copyright holder for this preprint (whA was not certified by peer review) is the author/funder, who has $\mathrm{g}$ Bnted bioRxiv a license to display the preprint in perpetuity. It is made Bothrops asper

\section{Daboia russelii russelii}
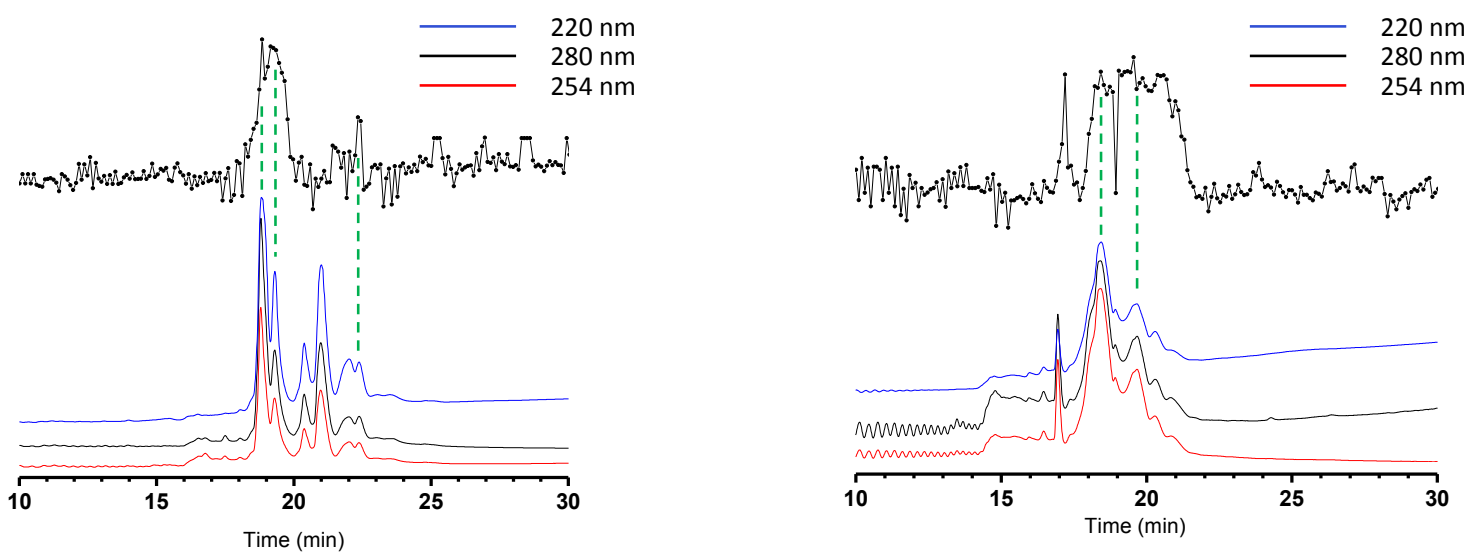

7C

7D

\section{Echis coloratus}

$220 \mathrm{~nm}$

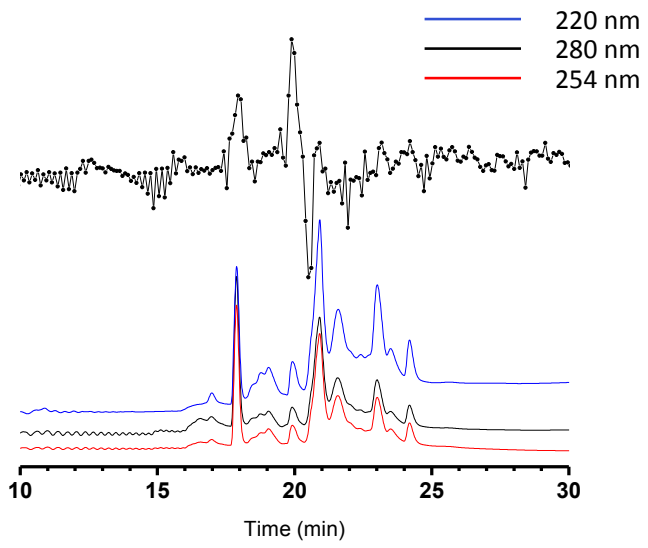

7E

7F

\section{Oxyuranus scutellatus}

Echis carinatus

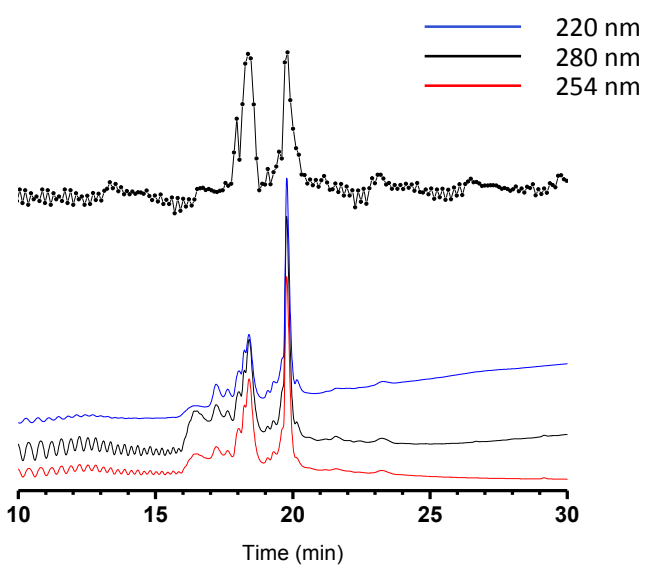


bioRxiv preprint doi: https://doi.org/10.1101/2020.01.20.912758; this version posted January 20, 2020. The copyright holder for this preprint (which was not certified by peer review) is the author/funder, who has granted bioRxiv a license to display the preprint in perpetuity. It is made available under aCC-BY-ND 4.0 International license.

\section{Bothrops asper}

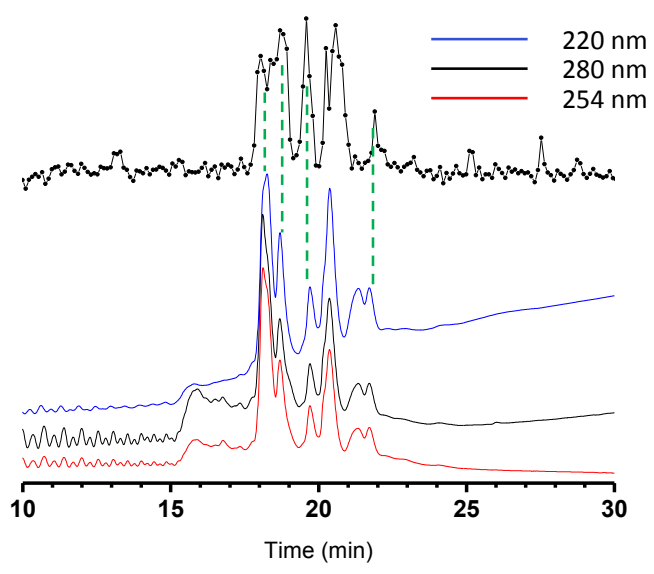

Still Figure 8 